\title{
Molecular mechanism of the RNA helicase DHX37 and its activation by UTP14A in ribosome biogenesis
}

\author{
FRANZISKA M. BONEBERG, ${ }^{1}$ TOBIAS BRANDMANN, ${ }^{1,3}$ LENA KOBEL, ${ }^{1,3}$ JASMIN VAN DEN HEUVEL, ${ }^{2,3}$ \\ KATJA BARGSTEN, ${ }^{1}$ LUKAS BAMMERT, ${ }^{2}$ ULRIKE KUTAY, ${ }^{2}$ and MARTIN JINEK ${ }^{1}$ \\ ${ }^{1}$ Department of Biochemistry, University of Zurich, CH-8057 Zurich, Switzerland \\ ${ }^{2}$ Department of Biology, Institute of Biochemistry, ETH Zurich, $\mathrm{CH}-8093$ Zurich, Switzerland
}

\begin{abstract}
Eukaryotic ribosome biogenesis is a highly orchestrated process involving numerous assembly factors including ATP-dependent RNA helicases. The DEAH helicase DHX37 (Dhr1 in yeast) is activated by the ribosome biogenesis factor UTP14A to facilitate maturation of the small ribosomal subunit. We report the crystal structure of DHX37 in complex with single-stranded RNA, revealing a canonical DEAH ATPase/helicase architecture complemented by a structurally unique carboxy-terminal domain (CTD). Structural comparisons of the nucleotide-free DHX37-RNA complex with DEAH helicases bound to RNA and ATP analogs reveal conformational changes resulting in a register shift in the bound RNA, suggesting a mechanism for ATP-dependent $3^{\prime}-5^{\prime}$ RNA translocation. We further show that a conserved sequence motif in UTP14A interacts with and activates DHX37 by stimulating its ATPase activity and enhancing RNA binding. In turn, the CTD of DHX37 is required, but not sufficient, for interaction with UTP14A in vitro and is essential for ribosome biogenesis in vivo. Together, these results shed light on the mechanism of DHX37 and the function of UTP14A in controlling its recruitment and activity during ribosome biogenesis.
\end{abstract}

Keywords: RNA helicase; X-ray crystallography; ribosome biogenesis

\section{INTRODUCTION}

Composed of four ribosomal RNAs (rRNAs) and $\sim 80$ proteins, eukaryotic ribosomes are complex ribonucleoprotein (RNP) nanomachines whose biogenesis is a highly orchestrated and regulated process (Kressler et al. 2017; Peña et al. 2017). Ribosome assembly starts in the nucleolus with the transcription of a large precursor, known as the $47 \mathrm{~S}$ preribosomal RNA (pre-rRNA) in mammalian cells, containing the future 18S, 5.8S and 28S rRNAs interspaced internally with noncoding internal transcribed spacers (ITS1 and ITS2) and flanked by $5^{\prime}$ and $3^{\prime}$ external transcribed spacers ( $5^{\prime}$ and $3^{\prime}$ ETS). The pre-rRNA transcript undergoes extensive processing and modification concurrently with RNA folding and ribosomal protein recruitment (Henras et al. 2015). An early cleavage event within ITS1 separates the 18S rRNA and 5.8S-28S rRNA fragments, leading to independent assembly pathways of the $40 \mathrm{~S}$ and 605 subunits, which are eventually exported to the cytoplasm for their final maturation. Eukaryotic ribosome biogenesis is dependent on $\sim 75$ small nucleolar RNAs (snoRNAs) that guide rRNA folding and site-specific mod-

${ }^{3}$ These authors contributed equally to this work.

Corresponding author: jinek@bioc.uzh.ch

Article is online at http://www.rnajournal.org/cgi/doi/10.1261/rna. 069609.118. Freely available online through the RNA Open Access option. ifications, and more than 200 protein assembly factors, including exo- and endonucleases, ATPases, GTPases, and DExH/D-box RNA helicases (Woolford and Baserga 2013). U3 small nucleolar RNA (snoRNA) is a key component of the small subunit (SSU) processome, an early stable intermediate of $40 \mathrm{~S}$ subunit assembly (Phipps et al. 2010). By hybridizing to the $5^{\prime}$-ETS and regions of the pre-18S rRNA, U3 facilitates initial folding of the pre-rRNA and formation of individual $18 \mathrm{~S}$ rRNA domains, and is required for nucleolytic cleavage within the 5' ETS and ITS1 (Beltrame and Tollervey 1992).

DExH/D-box ATPases belonging to the SF2 helicase superfamily use their ATP-dependent RNA binding or translocation activities to catalyze structural remodeling of RNAs or RNP complexes (Jankowsky and Fairman 2007; Fairman-Williams et al. 2010; Jankowsky 2011; Jarmoskaite and Russell 2014). Whereas DEAD-box helicases unwind RNA secondary structures by binding to and distorting RNA duplexes in an ATP-dependent manner (Yang et al. 2007; Hilbert et al. 2009), DEAH/RHA helicases (also termed DExH or DEAH helicases, and referred to as DEAH helicases herein) generally unwind RNA duplexes

(C) 2019 Boneberg et al. This article, published in RNA, is available under a Creative Commons License (Attribution-NonCommercial 4.0 International), as described at http://creativecommons.org/licenses/ by-nc/4.0/. 
or remodel RNPs by processive, ATP-driven translocation along an RNA strand in the $3^{\prime}-5^{\prime}$ direction (Büttner et al. 2007; Pyle 2008; He et al. 2010; Walbott et al. 2010; Linder and Jankowsky 2011). DExH/D-box helicases comprise a core module built of two RecA-like domains that utilize conserved sequence and structural motifs to bind ATP (motifs I, II, III, Va, and VI) and RNA (motifs la, Ib, Ic, IV, IVa, and V) (Jankowsky and Fairman 2007). Most DExH/D-box helicases do not possess intrinsic substrate specificity since RNA binding occurs via the ribose-phosphate backbone (Sengoku et al. 2006; Jankowsky 2011; Ozgur et al. 2015). Instead, they rely on protein cofactors for recruitment to specific RNAs and catalytic activation (Sloan and Bohnsack 2018). The specificity and catalytic activity of $\mathrm{DEAH}$ helicases is typically regulated by interactions with G-patch proteins (Robert-Paganin et al. 2015).

In yeast, 17 DExH/D-box RNA helicases are essential for ribosome biogenesis as they promote snoRNA removal and effect structural rearrangements in the assembling ribosomal subunits (Martin et al. 2014). The DEAH helicase Dhr1 is required for the assembly of the $40 \mathrm{~S}$ subunit (Colley et al. 2000; Granneman et al. 2006). Using its helicase activity, Dhr1 displaces U3 snoRNA from the 5'-terminal part of the pre-18S rRNA, thereby promoting the formation of the central pseudoknot, a critical step in the folding of the 18S rRNA (Sardana et al. 2015). Dhr1 is supported by the ribosomal biogenesis factor Utp14 and the rRNA methyltransferase-coactivator complex Bud23Trm112, both of which physically interact with the helicase and facilitate its efficient association with the preribosomal particle (Sardana et al. 2014; Zhu et al. 2016). Previous studies have suggested that Utp14, a stable component of the SSU processome, activates the RNA unwinding activity of Dhr1 in vitro and is required for the association of Dhr1 with the preribosome in vivo (Zhu et al. 2016). This suggests that Utp14 regulates the recruitment and activity of Dhr1 during the transition from the SSU processome to the pre-40S particle, and thereby the timing of the maturation of the $40 S$ subunit. Dhr1 and Utp14 have highly conserved mammalian orthologs, DHX37 and UTP14A, both of which have also been implicated in ribosome biogenesis (Choudhury et al. 2018). However, the structural and mechanistic details of the RNA remodeling activity of Dhr1/DHX37 and its stimulation by Utp14/ UTP14A remain elusive at present.

To obtain insights into the molecular mechanism of DHX37/Dhr1 helicases in ribosome biogenesis, we determined the crystal structure of murine DHX37 in complex with single-stranded RNA in the absence of adenosine nucleotide, which reveals a conformational state likely corresponding to a nucleotide exchange intermediate and suggests a mechanism for ATP-dependent $3^{\prime}-5^{\prime}$ RNA translocation. We further demonstrate that UTP14A stimulates both the ATPase and RNA binding activities of DHX37, thereby enhancing the processivity of the helicase.
Finally, we show that a structurally unique carboxy-terminal domain (CTD) of DHX37, absent from other DEAH helicases, is required for the interaction with UTP14A in vitro and the function of DHX37 in vivo. Combined, these insights shed light on the role of UTP14A in controlling the recruitment and activation of DHX37 during 405 subunit maturation.

\section{RESULTS AND DISCUSSION}

\section{Structure of DHX37 bound to ssRNA in the absence of adenosine nucleotide}

$\mathrm{DHX} 37$ is a $130 \mathrm{kDa}$ multidomain protein containing a canonical DEAH ATPase/helicase catalytic module that comprises two RecA-like (RecA1 and RecA2) domains and a helicase-associated domain (HA2), followed by an oligonucleotide/oligosaccharide-binding fold (OB) domain (Fig. 1A; Ozgur et al. 2015). The RecA1 domain is preceded by an extended region predicted to lack tertiary structure. Aiming to obtain structural insights into the molecular mechanism of $\mathrm{DHX} 37$, we expressed an amino-terminally truncated variant of murine DHX37 (MmDHX37) comprising amino acid residues 179-1150 (MmDHX37 $\left.{ }^{179-1150}\right)$. The RNA-dependent ATPase activity of MmDHX37 ${ }^{179-1150}$ was indistinguishable from that of full-length $\mathrm{MmDH} 37$, indicating that the amino-terminal region of $\mathrm{DHX} 37$ is not required for catalytic activity (Supplemental Fig. S1A; Supplemental Table S1). Fluorescence-polarization assays were used to monitor RNA binding, revealing that MmDHX37 ${ }^{179-1150}$ exhibited highest affinity for oligouridine RNA (Supplemental Fig. S1B). RNA binding was reduced in the presence of ADP or the nonhydrolyzable ATP analog AMPPNP (Supplemental Fig. S1C), indicating that $\mathrm{DHX} 37$ does not require adenosine nucleotides (ADP or ATP) for ssRNA binding and suggesting that RNA binding is weakened in the ATP- or ADP-bound states, as observed for other processive SF2 helicases (Levin et al. 2003; Robert-Paganin et al. 2016). This was corroborated by a pull-down experiment utilizing biotincoupled oligouridine RNA (Supplemental Fig. S1D), which confirmed that stable ssRNA binding is independent of adenosine nucleotides.

MmDHX37 $7^{179-1150}$ was subsequently crystallized in complex with uridine decanucleotide $\left(U_{10}\right)$, and its structure determined by single-wavelength anomalous $\mathrm{X}$-ray diffraction experiment. The structure was refined at a resolution of $2.9 \AA$ to an $R_{\text {work }}$ of $26.8 \%$ and $R_{\text {free }}$ of $29.7 \%$. The structure reveals a canonical DEAH ATPase/helicase architecture (Fig. 1B), in which the RecA-like, HA2, and OB-fold domains form a compact core, as previously observed in the structures of the related DEAH/RHA helicases Prp43 (He et al. 2017; Tauchert et al. 2017), MLE (Prabu et al. 2015), DHX36 (Chen et al. 2018b,c), and Prp2 (Schmitt et al. 2018). An additional $\alpha$-helical carboxy-terminal 
A

\begin{tabular}{|l|lll|ll|lll}
\hline & L & RecA1 & RecA2 & & HA2 & OB & CTD & \\
1231249 & 432 & & 688 & 912 & 1002 & & 1150
\end{tabular}

B

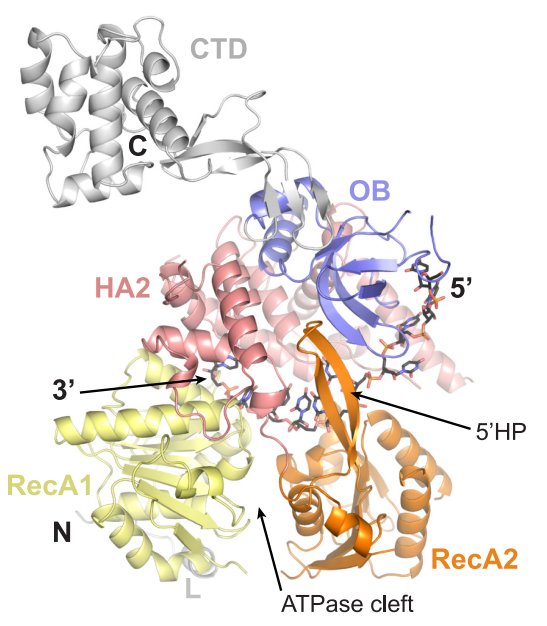

C

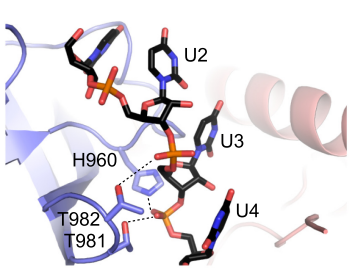

D

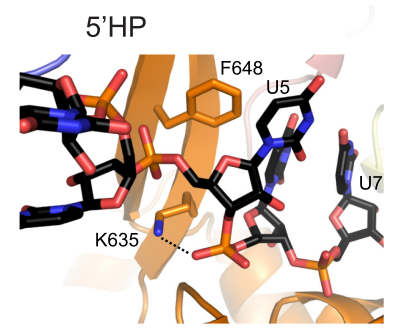

E

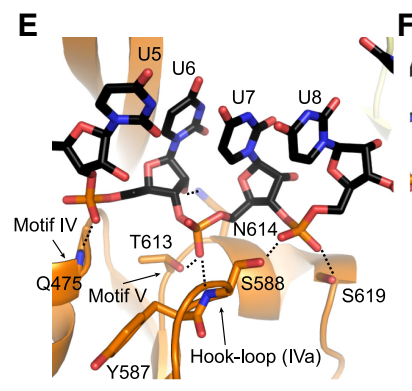

$\mathbf{F}$

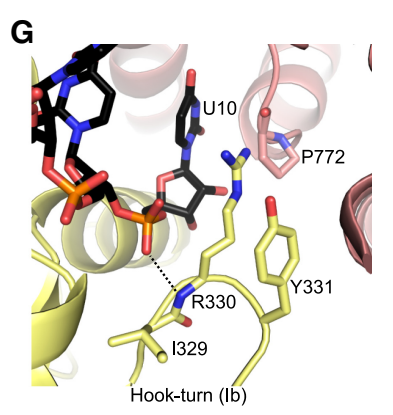

Hook-turn ( $\mid$ b)

FIGURE 1. Structure of the DHX37-RNA complex in adenosine nucleotide-free state. (A) Schematic of the domain architecture of MmDHX37. The crystallized protein comprises residues 179-1150. (L) linker domain, (RecA1) RecA-like domain 1, (RecA2) RecA-like domain 2, (HA2) helicase-associated domain 2, (OB) Oligonucleotide-binding fold domain, (CTD) carboxy-terminal domain. (B) Overall structure of the MmDHX37 $7^{19-1150}-U_{10}$ RNA complex. The helicase is shown in cartoon format and colored according to the scheme in $A$. The bound RNA is colored black and shown in stick format. The amino-/carboxy- and $5^{\prime}-/ 3^{\prime}$-termini of the DHX37 polypeptide and the RNA are indicated. 5'HP: 5' hairpin motif. (C) Zoom-in view of RNA nucleotides U1-U4. Hydrogen bonding interactions are indicated with dashed black lines. (D) Zoom-in view of the 5'HP and RNA nucleotides U3-U7. (E) Zoom-in view of nucleotides U5-U8 binding to helicase motifs IV, Iva, and V. (F) Zoom-in view of nucleotides U8-U10 binding to helicase motif Ic. (G) Zoom-in view of nucleotides U9-U10 binding to helicase motif lb (hook-turn).

domain (CTD, Fig. 1A), a distinct feature of DHX37 orthologs, projects away from the helicase core (Fig. 1B). The CTD has a unique fold not observed in other proteins and makes few contacts with the helicase core, its orientation being maintained by crystal contacts with a second DHX37 molecule in the asymmetric unit of the crystal. In solution, the CTD is thus likely to be flexibly tethered to the helicase core and conformationally dynamic.

Although the MmDHX37 ${ }^{179-1150}-\mathrm{U}_{10}$ complex was crystallized in the presence of the nonhydrolyzable ATP analog AMPPNP, no corresponding electron density could be observed in the ATPase active site located at the interface of the RecA1 and RecA2 domains. Structural comparison of the DHX37- $U_{10}$ complex with that of Chaetomium thermophilum Prp43 bound to $U_{7}$ RNA and the transition state analog ADP.BeF${ }_{3}^{-}$(Tauchert et al. 2017) reveals that the DHX37 ATPase active site has an open conformation in which conserved active site motifs involved in ATP and $\mathrm{Mg}^{2+}$ coordination (Supplemental Fig. S3) adopt conformations incompatible with high-affinity ATP binding (Supplemental Fig. S4). In particular, superposition of the RecA1 domains of the DHX37 and Prp43 complexes shows that active site motifs $\mathrm{Va}$ and $\mathrm{VI}$ in the DHX37 RecA2 domain are displaced by $\sim 7 \AA$ away from the position that they assume in the ATP-bound conformation in Prp43 (Supplemental Fig. S4C) and other DEAH helicases (Prabu et al. 2015; He et al. 2017; Tauchert et al. 2017; Schmitt et al. 2018).

The $U_{10} R N A$ is bound predominantly by sequence nonspecific ionic and hydrogen-bonding interactions with the ribose-phosphate backbone (Supplemental Fig. S2B), as observed for other DEAH helicases (Prabu et al. 2015; He et al. 2017; Tauchert et al. 2017; Chen et al. 2018b,c). DHX37 makes base-directed interactions only with nucleotides U1, U5 and U9 (Supplemental Fig. S5), which may contribute to the observed binding preference of DHX37 for uridine-rich RNA (Supplemental Fig. S1B). The 5 '-terminal part of the RNA binds in a surface cleft along the OB domain, with phosphate groups of nucleotides $\mathrm{U} 3$ and U4 contacted by two threonine residues in the $\beta 20-\beta 21$ loop in the OB domain and by His960 in the $\beta 18-\beta 19$ loop (Fig. 1C). In turn, nucleotides U5-U10 are bound in a central channel within the helicase core, surrounded by the RecA1, RecA2, HA2, and OB domains. Throughout the channel, the RNA is stabilized by ionic interactions with the basic side chain groups of phylogenetically conserved amino acid residues Lys635 (RecA2 domain), Arg803 (HA2), Arg303, Arg304, and Arg330 (all RecA1). At the 5'-proximal end of the RNA-binding channel, the RNA backbone passes through a narrow opening formed by the HA2 and OB domains and a long $\beta$-hairpin that extends from the RecA2 domain and contacts the HA2 and $\mathrm{OB}$ domains. The $\beta$-hairpin $\left(5^{\prime} \mathrm{HP}\right)$, which is a characteristic feature of the DEAH helicases (He et al. 2017), packs 
against nucleotide U5 forming a $5^{\prime}$-terminal bookend for the RNA nucleotides bound in the helicase channel (Fig. 1D). The 5'HP may additionally provide a physical barrier to induce the unwinding of secondary structures in RNA or remodeling of protein-RNA interactions during $3^{\prime}-5^{\prime}$ translocation, as has been proposed for other SF2 superfamily RNA helicases (Büttner et al. 2007; Pyle 2008; Ozgur et al. 2015; He et al. 2017; Tauchert et al. 2017). Five nucleotides (U6-U10) are accommodated in the central part of the RNA binding channel. The bases of nucleotides U6-U10 form a continuous stack, while their ribosephosphate backbone makes numerous contacts with the RNA binding motifs IV, V, and VI in the RecA2 domain and motifs $\mathrm{lb}$ and $\mathrm{lc}$ in the RecA1 domain (Fig. 1E-G). Specifically, motif IV contacts the phosphate group of U6 via hydrogen-bonding interaction with the backbone amide of Gln475. An invariant threonine residue in motif $\mathrm{V}$ (Thr613) interacts with the phosphate group of U7. Motif IVa, also described as the hook-loop (Prabu et al. 2015), binds the phosphate groups of U7 and U8 by hydrogenbonding interactions with the backbone amide and side chain groups of Ser588, respectively (Fig. 1E). In the 3'proximal part of the RNA-binding channel, the ribose-phosphate moieties of nucleotides $U 9$ and U10 interact with the RecA1 domain. The backbone amide group of Arg304 makes a hydrogen-bonding interaction with the phosphate group of U9, while the 2'-hydroxyl group of U9 is contacted by the side-chain carboxyl group of Asp346 (Fig. 1F). The phosphate group of U10 is bound by hydrogen-bonding interactions with the invariant residue Thr345 of motif Ic and the backbone amide of Arg330 of motif lb (Fig. 1F), also referred to as the hook-turn (Tauchert et al. 2017). Arg330 and Tyr331 in motif lb, together with invariant residue Pro772 in the $\alpha 15-\alpha 16$ loop of the HA2 domain, line the 3 '-terminal exit of the RNA binding channel, forming a 3 '-terminal bookend for the bound RNA (Fig. 1G).

Altogether, the structure of the $\mathrm{DHX} 37-\mathrm{U}_{10}$ complex reveals the RNA binding mode of DHX37 in the absence of adenosine nucleotide (ATP or ADP), which likely corresponds to a nucleotide exchange state of the helicase upon the dissociation of ATP hydrolysis products (ADP and inorganic phosphate) and prior to the binding of the next ATP molecule in the catalytic cycle. The conformation of the DHX37 helicase core and its RNA binding mode bears resemblance to the structures of the related helicase DHX36 bound to a DNA substrate in the absence of ATP (Chen et al. 2018b,c), suggesting that the ATP-free conformation is conserved across the DEAH helicase family (Supplemental Fig. S6).

\section{RNA binding mode reveals the $3^{\prime}-5^{\prime}$ translocation mechanism of DHX37}

DEAH RNA helicases are generally thought to catalyze the unwinding of RNA secondary structures or remodeling of
protein-RNA complexes by ATP-powered translocation along a tracking RNA strand in the $3^{\prime}-5^{\prime}$ direction (Ozgur et al. 2015). In this process, the helicases cycle through ATP-, ADP-bound, and nucleotide-free conformational states, in which ATP nucleotide binding at the interface of the RecA1 and RecA2 domains allosterically induces structural transitions in the RNA binding sites. Although the translocation directionality of DHX37 (or Dhr1) has not been formally demonstrated, Prp43, a close homolog of DHX37 within the DEAH family ( 39\% sequence identity within the helicase cores of human DHX37 and DHX15/ Prp43), is a bona fide $3^{\prime}-5^{\prime}$ helicase (He et al. 2017).

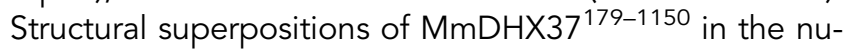
cleotide-free state with Prp43 in complexes with oligo- $U$ RNAs and ATP analogs reveal major conformational differences in the relative orientations of the RecA1 and RecA2 domains, reflecting an open conformation of the ATPase site in DHX37 and a closed conformation in ATP analogbound Prp43 (He et al. 2017; Tauchert et al. 2017). Structural analysis using the DynDom server (Hayward and Berendsen 1998) further indicates that the RecA2 domain of $\mathrm{DHX} 37$ must rotate by $\sim 14^{\circ}$ with respect to RecA1 in order to assume the ATP-bound conformation, while the HA2 and $\mathrm{OB}$ domains undergo a minor $\sim 2^{\circ}$ rotation combined with a $2 \AA$ shift relative to RecA1 (Fig. 2A,B). The conformational differences between the ATP-free and ATP analog-bound states are reflected in distinct RNA binding modes observed in the complexes. Whereas DHX37 in the ATP-free state encloses a 5-nt stack within the RNA binding tunnel, Prp43 in the ATP-bound state accommodates a 4-nt stack (Fig. 2C,D). In both states, the $5^{\prime}$ and $3^{\prime}$ termini of the nucleotide stacks are supported by the $5^{\prime} \mathrm{HP}$ and motif lb hook-turn, respectively. As a consequence of the open conformation of the RecA1 and RecA2 domains, the RNA-interacting motifs in the RecA2 domain, including motif $V$ containing Thr613, shift by one nucleotide toward the $5^{\prime}$ end of the RNA (Fig. 2D). Conversely, while Thr613 remains in contact with the phosphate moiety of nucleotide $\mathrm{N}$, the invariant Thr345 of motif Ic that interacts with the phosphate of nucleotide $\mathrm{N}+3$ in the ATP-free state would contact nucleotide $\mathrm{N}+2$ in the ATP-bound state upon closure of the RecA1 and RecA2 domains (Fig. 2C).

Together, the structural insights provided here suggest a model for ATP-dependent $3^{\prime}-5^{\prime}$ translocation in DHX37 and other DEAH helicases, in which ATP binding at the interface of the RecA1 and RecA2 domains induces a conformational closure that is propagated to the RNA binding channel. By maintaining interactions with motifs IV, IVa and $V$ and the $5^{\prime} \mathrm{HP}$ in RecA2, the RNA is shifted by one nucleotide along RecA1 and the 3'-terminal nucleotide exits past the hook-turn motif. Upon ATP hydrolysis and ADP/ $\mathrm{Pi}$ release, the helicase reverts to the open conformation, which allows the RecA2 domain to undergo a register shift and engage the next 5'-terminal nucleotide, while motifs $\mathrm{Ic}$ and $\mathrm{lb}$ (hook-turn) in RecA1 remain tightly bound to the 

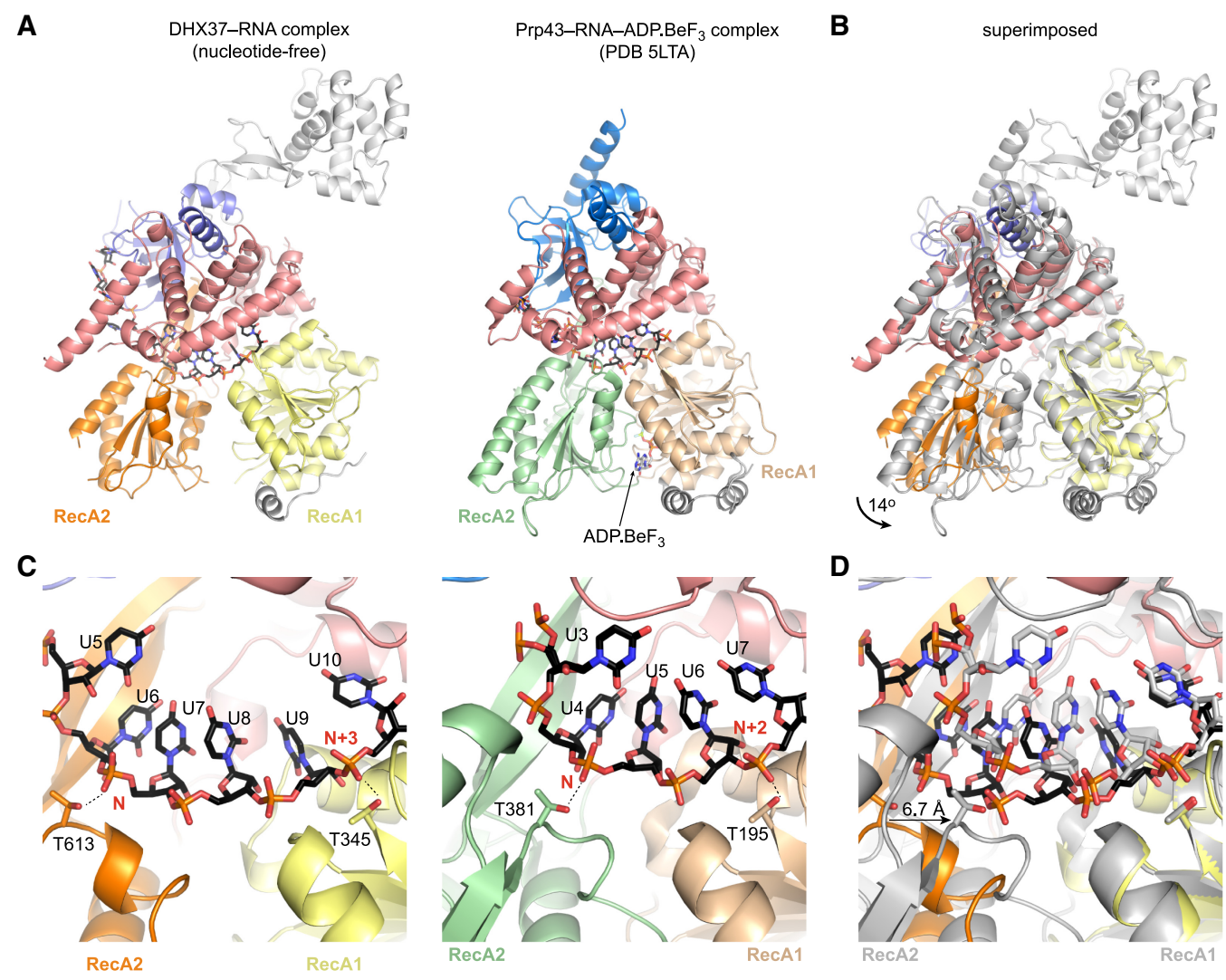

FIGURE 2. RNA binding mode of DHX37 suggests a mechanism for ATP-driven $3^{\prime}-5^{\prime}$ translocation. (A) Side-by-side comparison of the structures of the DHX37-RNA (left) and Prp43-RNA-ADP. $\mathrm{BeF}_{3}{ }^{-}$(PDB entry 5LTA, right) complexes. The helicases were superimposed using their RecA1 domains and are shown in identical orientations. (B) Superposition of DHX37 (colored as in A) and Prp43 (colored gray). The ADP.BeF ${ }_{3}{ }^{-}$transition state mimic is shown in stick format. (C) Side-by-side views of the RNA binding channels in the DHX37-RNA (left) and Prp43-RNA-ADP.BeF ${ }_{3}$ (right) complexes. While DHX37 accommodates a 5-nt stack (U6-U10) in the ATP-free state, Prp43 accommodates a 4-nt stack (U4-U7) in the ADP. $\mathrm{BeF}_{3}^{-}$bound state. Motif IVa is omitted from the figures to give unobstructed view of the bound RNA. (D) Superposition of the RNA binding channels in DHX37 (colored as in A) and Prp43 (gray).

$3^{\prime}$-terminal part of the RNA. In this mechanism, the helicase toggles between states in which 4- and 5-nt RNA stacks are accommodated in the RNA binding channel, which would be consistent with an "expansion" model of helicase translocation proposed by earlier studies (Supplemental Fig. S7; Pyle 2008; He et al. 2017; Chen et al. 2018a; Hamann et al. 2019). Notably, the model posits that ATP binding, rather than hydrolysis, provides the power stroke for translocation. This might explain previous observations that under presteady state conditions, yeast Dhr1 is able to unwind short RNA duplexes in an ATP-dependent manner but in the absence of actual ATP hydrolysis, since translocation along a single nucleotide might be sufficient to induce duplex unwinding in this case (Sardana et al. 2015).

\section{A short motif in UTP14A activates DHX37 by stimulating its ATPase activity and enhancing RNA binding}

In yeast, the ribosome biogenesis factor Utp14 associates with Dhr1, the ortholog of DHX37, recruiting it to the preri- bosomal particle and stimulating its RNA helicase activity to facilitate the dissociation of U3 snoRNP from the maturing $40 S$ ribosomal subunit (Zhu et al. 2016). Utp14 directly interacts with Dhr1 in vitro and enhances its RNA unwinding activity (Zhu et al. 2016). To investigate whether the mammalian ortholog UTP14A has a similar effect on DHX37, we coexpressed MmDHX37 $7^{179-1150}$ together with fulllength human UTP14A in baculovirus-infected insect cells and succeeded in purifying the resulting complex, confirming a direct physical interaction between DHX37 and UTP14A (Supplemental Fig. S8). We subsequently measured the ATPase activity of isolated MmDHX37179-1150 and the MmDHX37 ${ }^{179-1150}$-UTP14A complex. At physiological ATP concentrations (2 mM), the ATPase activity of the MmDHX37 ${ }^{179-1150}$-UTP14A complex was $~ 15$-fold higher than that of MmDHX37 $7^{179-1150}$ alone (Supplemental Fig. 9A,B; Supplemental Table S1), suggesting that UTP14A functions as an activator of DHX37 in part by increasing its RNA-dependent ATPase activity. This result stands in contrast to a previous observation that yeast Utp14 increases the RNA unwinding activity of Dhr1 in vitro 
without affecting ATPase activity (Zhu et al. 2016) but is in good agreement with a recent study of human DHX37 (Choudhury et al. 2018). Although DHX37 and Dhr1 have similar biological functions, it is possible that they use divergent molecular mechanisms.

Recent structural studies of the yeast SSU processome showed that Utp14 is an intrinsically unfolded, extended protein whose amino-terminal and carboxy-terminal regions participate in SSU processome assembly by making extensive contacts with other ribosome biogenesis factors including Utp6, Sof1, and Utp7 (Barandun et al. 2017; Cheng et al. 2017; Black et al. 2018). The intervening region (Supplemental Fig. S10A), which is disordered in the SSU processome structures, has been shown to be necessary for interaction with Dhr1 (Zhu et al. 2016). To define the region in human UTP14A responsible for interaction with DHX37, we expressed a series of truncated protein constructs in human cells and tested their

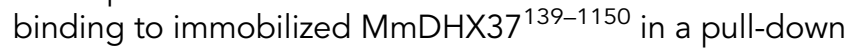
assay. A UTP14A protein fragment comprising residues Lys555-Ser619 was efficiently coprecipitated by MmDHX37 $7^{139-1150}$ (Fig. 3A), while further amino- and carboxy-terminal truncations abolished binding (Fig. 3B), suggesting that this region (hereafter referred to as UTP14A ${ }^{\mathrm{min}}$ ) is the minimal motif necessary and sufficient for interaction with $\mathrm{DHX} 37$. Purified recombinant UTP14A ${ }^{\mathrm{min}}$ protein was also sufficient to activate DHX37 in vitro, enhancing its ATPase activity by a factor of $\sim 14$, indicating that the stimulatory effect can be attributed solely to the minimal region necessary for physical interaction with DHX37 (Supplemental Fig. S9C,D; Supplemental Table S1). UTP14A $A^{\text {min }}$ contains two conserved sequence motifs; the amnio-terminal motif (Met558-Leu561) is conserved in metazoan DHX37 orthologs, while the carboxy-terminal motif (Met594-Glu597) is highly conserved across all eukaryotes including yeast (Supplemental Fig. S10B). Mutation of the amino-terminal motif residues to alanine reduced binding to $\mathrm{MmDH} \times 37^{139-1150}$, while mutation of the carboxy-terminal motif completely abolished interaction with $\mathrm{MmDHX37^{139-1150 }}$ (Fig. 3B). Accordingly, the carboxy-terminal motif mutant UTP14A ${ }^{\text {min }}$ protein failed to stimulate the RNA-dependent ATPase activity of MmDHX37 $7^{179-1150}$ in vitro, while the activating effect of the amino-terminal motif mutant protein was substantially reduced (Supplemental Fig. 9C,D). Together, these experiments demonstrate that a conserved motif in the central region of UTP14A physically interacts with DHX37 and allosterically activates its ATPase activity. This is consistent with prior genetic experiments showing that point mutations and deletions in the corresponding region of yeast Utp14 perturb its interaction with Dhr1 and impair the function of Dhr1 in ribosome biogenesis (Zhu et al. 2016). Although UTP14A orthologs contain a highly conserved glycine-rich sequence (Gly630-Gly638 in human UTP14A, Supplemental Fig. S10B) somewhat reminiscent of the G-patch protein consensus motif, our deletion analysis indicates that this sequence in UTP14A is neither required for the interaction with DHX37 nor for the enhancement of its ATPase activity. This suggests that UTP14A is not a canonical G-patch protein, as proposed previously (Zhu et al. 2016).

To investigate the mechanism underpinning UTP14Amediated activation of DHX37, we analyzed the ATPase ac-

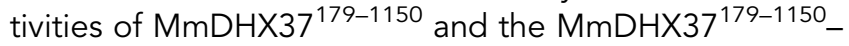
UTP14A $^{\text {min }}$ complex as a function of ATP and RNA concentrations. UTP14A ${ }^{\text {min }}$ enhanced the ATPase activity of $\mathrm{DHX} 37$ in the presence of $1.5 \mu \mathrm{M} U_{10}$ RNA by increasing $k_{\text {cat }}$ by approximately eightfold, while simultaneously reducing the Michaelis constant $\left(K_{M}\right)$ for ATP by $\sim 2.7$-fold (Table 1; Fig. 3C). The half-maximal effective concentration $\left(E C_{50}\right)$ of $U_{10}$ RNA was reduced by a factor of $\sim 60$-fold in the presence of UTP14A ${ }^{\min }$ (Table 1; Fig. 3D). Together, these results suggest that UTP14A-mediated stimulation of the RNA-dependent ATPase activity of $\mathrm{DH} 37$ is in large part due to enhancement of RNA binding. To corroborate our kinetics measurements, we examined the ssRNA binding activities of $\mathrm{MmDHX37^{179-1150 }}$ and the MmDHX37 ${ }^{179-1150}-U T P 14 A^{\min }$ complex in the absence and presence of adenosine nucleotides using fluorescence polarization (FP) (Fig. 3E). In the absence of adenosine nucleotides, UTP14A ${ }^{\text {min }}$ stimulated the binding of $U_{10}$ RNA by approximately twofold. However, in the presence of ADP or AMPPNP, the MmDHX37 $7^{179-1150}$ UTP14A ${ }^{\text {min }}$ complex displayed a $\sim 25$-fold or $\sim 10$-fold higher affinity, respectively, for $U_{10}$ than $M m D H X 37^{179-1150}$ alone (Fig. 3E). This indicates that the interaction with UTP14A increases the nucleotide-dependent RNA binding activity of DHX37 and that the increase is commensurate with the observed enhancement of ATPase activity engendered by UTP14A (Supplemental Fig. S9). Collectively, these results imply that UTP14A stimulates the activity of DHX37 by functioning as a processivity factor that enhances nucleotide-dependent RNA binding, thereby increasing the mechanochemical coupling between ATP binding/ hydrolysis and RNA translocation. This mechanism thus likely underpins the regulation of the ATP-dependent RNA translocation activity of DHX37, which is essential for the remodeling of the U3 snoRNA-pre-18S rRNA structure during 405 maturation.

\section{The carboxy-terminal domain of $\mathrm{DHX} 37$ is essential for UTP14A binding in vitro and ribosome biogenesis in vivo}

G-patch proteins activate DEAH RNA helicases by interactions with the OB domain (Tanaka and Schwer 2005; Lebaron et al. 2009; Chen et al. 2014; Robert-Paganin et al. 2015; Heininger et al. 2016). As prior studies (Zhu et al. 2016) and our biochemical experiments suggested that UTP14A is functionally distinct from canonical G-patch 
A

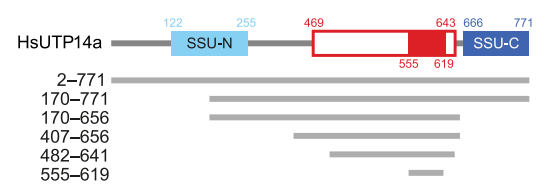

$5 \%$ input Strep-MmDHX37 $7^{139-1150}$

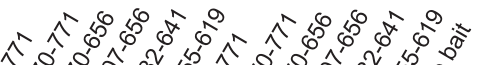

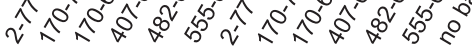
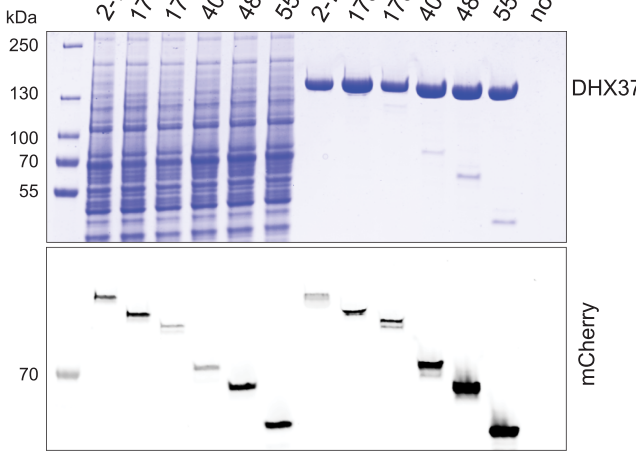

C

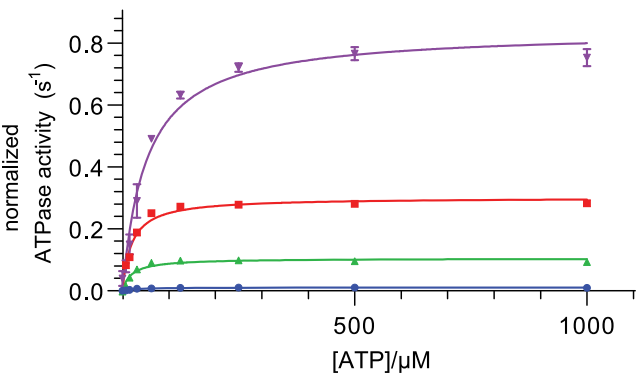

- DHX37-UTP14a ${ }^{\min }(0.125 \mu \mathrm{M})+\mathrm{U}_{10}$ RNA $(1.5 \mu \mathrm{M})$

$\rightarrow$ DHX37-UTP14a ${ }^{\min }(0.125 \mu \mathrm{M})+\mathrm{U}_{10}$ RNA $(0.18 \mu \mathrm{M})$

$\rightarrow \operatorname{DHX37}(1.0 \mu \mathrm{M})+\mathrm{U}_{10}$ RNA $(1.5 \mu \mathrm{M})$

$\rightarrow \operatorname{DHX} 37(2 \mu \mathrm{M})$

E

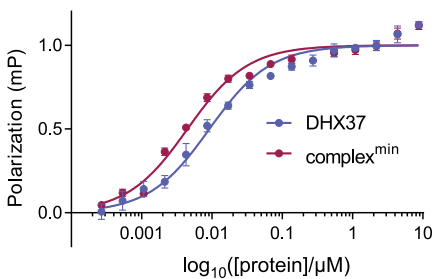

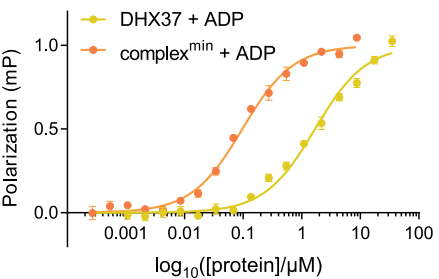

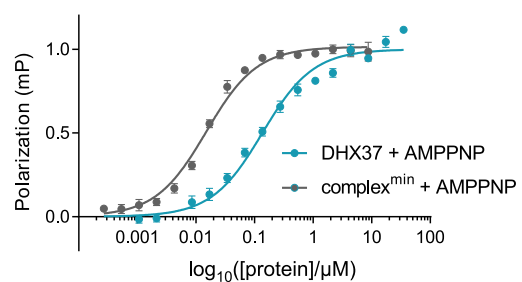

FIGURE 3. UTP14A stimulates ATPase activity of DHX37 and enhances RNA binding. ( $A$, top) Schematic diagram of human UTP14A and constructs used for pull-down experiment. SSU-N and SSU-C denote the amino- and carboxy-terminal regions corresponding to the regions of Utp14 bound in the yeast SSU processome structure. Red boundary denotes region corresponding to the Dhr1 interacting region in yeast Utp14. Solid red box denotes minimal region in HsUTP14A required for interaction with DHX37. (Bottom) SDS-PAGE analysis of streptactin pull-down experiment using Strepll-tagged MmDHX37 ${ }^{139-1150}$ as bait and indicated mCherry-tagged HsUTP14A constructs as prey. UTP14A constructs are visualized by $m$ Cherry fluorescence. $(B$, top) Schematic diagram of human UTP14A and constructs used for pull-down experiment. (Bottom) SDS-PAGE analysis of streptactin pull-down experiment using Strepll-tagged MmDHX37 $7^{139-1150}$ as bait and indicated mCherry-tagged HsUTP14A constructs as prey. MIEF denotes the M594A/I595A/E597A/F599A quadruple point mutant; MIDL denotes the M558A/I559A/D560A/ L561A mutant. (C) RNA-dependent ATPase activity of MmDHX37 ${ }^{179-1150}$ or the MmDHX37 ${ }^{179-1150}-$ HsUTP14A ${ }^{\text {min }}$ complex as a function of ATP concentration. The data were subjected to Michaelis-Menten analysis and the calculated $k_{\text {cat }}$ and $K_{M}$ values are provided in Table 1. Experiments were performed in triplicates, with data points indicating the mean and error bars indicating the standard error of the mean. (D) RNA-dependent ATPase activity of MmDHX37 ${ }^{179-1150}$ or the MmDHX37 ${ }^{179-1150}-H s U T P 14 A^{\text {min }}$ complex as a function of $\mathrm{U}_{10}$ RNA concentration. Experiments were performed in triplicates, with data points indicating the mean and error bars indicating the standard error of the mean. $E_{50}$ values are provided in Table 1. (E) Fluorescence-polarization equilibrium binding assays of MmDHX37 ${ }^{179-1150}$ or the MmDHX37 $7^{179-1150}-H_{s}$ UTP14A ${ }^{\text {min }}$ complex with ATTO532 fluorophore-labeled $U_{12}$ RNA in the absence of adenosine nucleotides (left) and in the presence of ADP (center) and the nonhydrolyzable ATP analog AMPPNP (right). $K_{d}$ values are provided in Table 1. 
TABLE 1. Kinetic and thermodynamic parameters of DHX37 and the DHX37-UTP14A complex

\begin{tabular}{|c|c|c|c|}
\hline Enzyme & RNA & $K_{\mathrm{m}}(\mu \mathrm{M})$ & $k_{\text {cat }}\left(s^{-1}\right)$ \\
\hline \multicolumn{4}{|l|}{ ATPase activity } \\
\hline $\mathrm{MmDH} \times 37^{179-1150}$ & - & $28.30 \pm 2.92$ & $0.0108 \pm 0.0001$ \\
\hline $\mathrm{MmDH} \times 37^{179-1150}(1.0 \mu \mathrm{M})$ & $\mathrm{U}_{10}(1.5 \mu \mathrm{M})$ & $19.26 \pm 4.79$ & $0.105 \pm 0.003$ \\
\hline 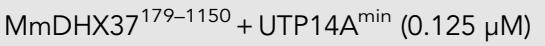 & $\mathrm{U}_{10}(1.5 \mu \mathrm{M})$ & $52.61 \pm 4.78$ & $0.844 \pm 0.009$ \\
\hline $\mathrm{MmDH} \times 37^{179-1150}+\mathrm{UTP}^{14 \mathrm{~A}^{\min }}(0.125 \mu \mathrm{M})$ & $\mathrm{U}_{10}(0.188 \mu \mathrm{M})$ & $19.95 \pm 0.75$ & $0.301 \pm 0.001$ \\
\hline Enzyme & & & \\
\hline \multicolumn{4}{|c|}{$\mathrm{EC}_{50}$ of $\mathrm{U}_{10}$ RNA for ATPase activation (ATPase activity measured at $1 \mathrm{mM}$ ATP) } \\
\hline $\mathrm{MmDH} \times 37^{179-1150}$ & & & \\
\hline $\mathrm{MmDHX} 37^{179-1150}+\mathrm{UTP}^{14 \mathrm{~A}^{\mathrm{min}}}$ & & & \\
\hline Enzyme & Nucleotide & $K_{\mathrm{d}}(\mathrm{nM})$ & \\
\hline \multicolumn{4}{|c|}{ Equilibrium dissociation constants for $\mathrm{U}_{10} \mathrm{RNA}$ binding } \\
\hline $\mathrm{MmDHX37^{179-1150 }}$ & - & $9.83 \pm 0.55$ & \\
\hline $\mathrm{MmDH} \times 37^{179-1150}+\mathrm{UTP}^{14 A^{\min }}$ & - & $4.19 \pm 0.27$ & \\
\hline $\mathrm{MmDHX37^{179-1150 }}$ & ADP (1 mM) & $2133 \pm 316$ & \\
\hline $\mathrm{MmDHX} 37^{179-1150}+\mathrm{UTP}^{14 \mathrm{~A}^{\mathrm{min}}}$ & ADP (1 mM) & $86.06 \pm 13.8$ & \\
\hline $\mathrm{MmDHX37^{179-1150 }}$ & AMPPNP (1 mM) & $135.13 \pm 2.41$ & \\
\hline MmDHX37 $7^{179-1150}+$ UTP14A ${ }^{\min }$ & AMPPNP (1 mM) & $14.61 \pm 0.26$ & \\
\hline
\end{tabular}

proteins, we next sought to pinpoint the specific domains in DHX37 involved in the interaction with UTP14A, focusing on the unique CTD of DHX37. We expressed full-length MmDHX37 and a truncated variant comprising amino acid residues 2-1003 (MmDHX37 ${ }^{\triangle \mathrm{CTD}}$ ) in human cells and tested their binding to immobilized UTP14A ${ }^{\text {min }}$ in a pull-down experiment. Whereas MmDHX37 was efficiently coprecipitated by UPT14A from cell lysate, $\mathrm{MmDH} 37^{\triangle \mathrm{CTD}}$ was not, indicating that the CTD is required for stable interaction with UTP14A (Fig. 4A). The RNA-dependent ATPase activity of $\mathrm{MmDHX37^{ \triangle CTD }}$ was similar to that of MmDHX37 $7^{179-1150}$ (Supplemental Fig. S11A). Crucially, the ATPase activity was not enhanced in the presence of UTP14A, indicating that the CTD is required both for the interaction with UTP14A and for UTP14A-mediated stimulation of the ATPase activity of DHX37 (Supplemental Fig. S11A). However, subsequent pull-down experiments revealed that purified recombinant DHX37 CTD (comprising amino acid residues 1003-1150) did not interact with UTP14A ${ }^{\text {min }}$ (Supplemental Fig. S11B, C), indicating that although essential, the CTD is not sufficient to mediate a stable interaction with UTP14A.

To further test the requirement of the CTD for the function of $\mathrm{DHX} 37$ in ribosome biogenesis, we used a previously established reporter assay to examine the effect of overexpressing wild-type and mutant MmDHX37 proteins on the biogenesis of the $40 S$ subunit. In this assay, nucleolar retention of the biogenesis factor ENP1 upon treatment with the nuclear export inhibitor LMB is indicative of an early $40 \mathrm{~S}$ biogenesis defect (Badertscher et al. 2015). Overex- pression of the ATPase-deficient E3690 point mutant resulted in nucleolar retention of ENP1, indicating that catalytically inactive DHX37 acts as a dominant-negative inhibitor of $40 \mathrm{~S}$ biogenesis (Fig. 4B; Supplemental Fig. S11D). In contrast, overexpression of neither full-length wild-type MmDHX37 nor a catalytically active MmDHX37 lacking the CTD (MmDHX37 ${ }^{\triangle C T D}$ ) had a dominant-negative effect on $40 S$ biogenesis. Notably, nucleolar localization of $\mathrm{MmDH} \times 37^{\triangle \mathrm{CTD}}$ was not perturbed, indicating that the protein is folded and the CTD is not required for the nuclear import of DHX37 (Fig. 4B). To complement these results, we tested the ability of ectopically expressed fulllength and $\mathrm{MmDH} 37^{\triangle \mathrm{CTD}}$ proteins to rescue the $40 \mathrm{~S}$ biogenesis defect caused by depletion of endogenous DHX37 in HeLa cells. To this end, we utilized CRISPR interference to target the promoter of the endogenous DHX37 gene, thereby down-regulating its expression, in cells stably transfected with MmDHX37 expression plasmids (Supplemental Fig. S11E). CRISPRi-targeted cells expressing $\mathrm{MmDH} 37^{\triangle \mathrm{CTD}}$ exhibited nucleolar localization of ENP1 in the presence of $\mathrm{LMB}$, indicating that $\mathrm{MmDH} \times 37^{\triangle \mathrm{CTD}}$ was unable to rescue the early 405 biogenesis defect phenotype caused by DHX37 depletion, whereas expression of full-length $\mathrm{MmDHX} 37$ restored normal localization of ENP1 (Fig. 4C). Together, these observations indicate that the CTD of DHX37 is required for 405 biogenesis in vivo.

The current model for the function of DHX37/UTP14A, based on genetic and biochemical studies of yeast Dhr1/Utp14 (Zhu et al. 2016), posits that DHX37 is 
A

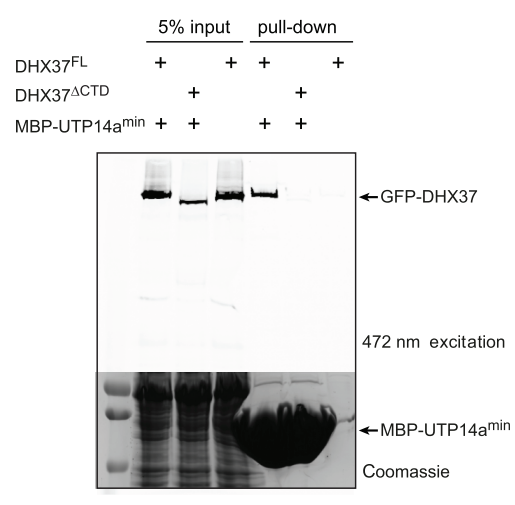

B

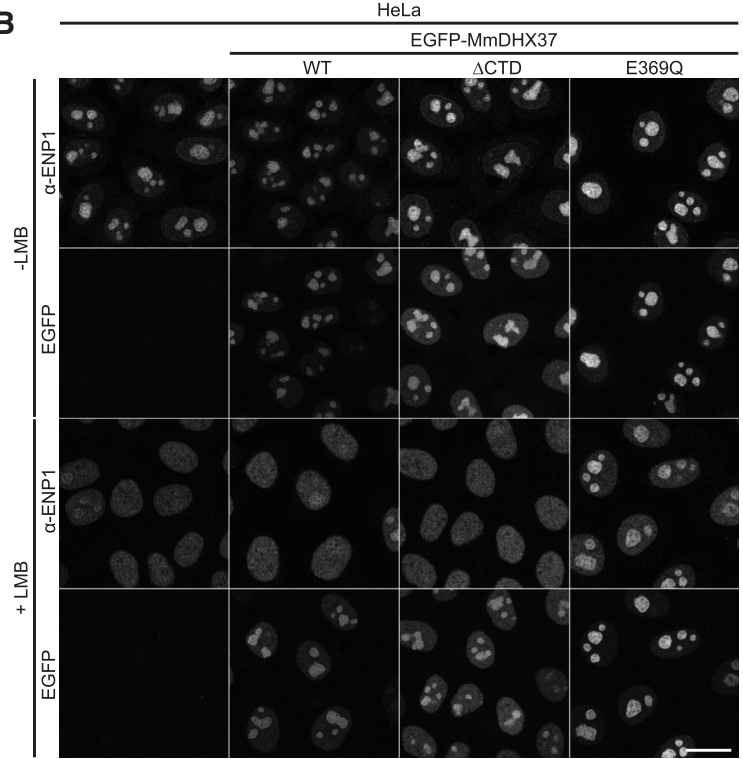

C

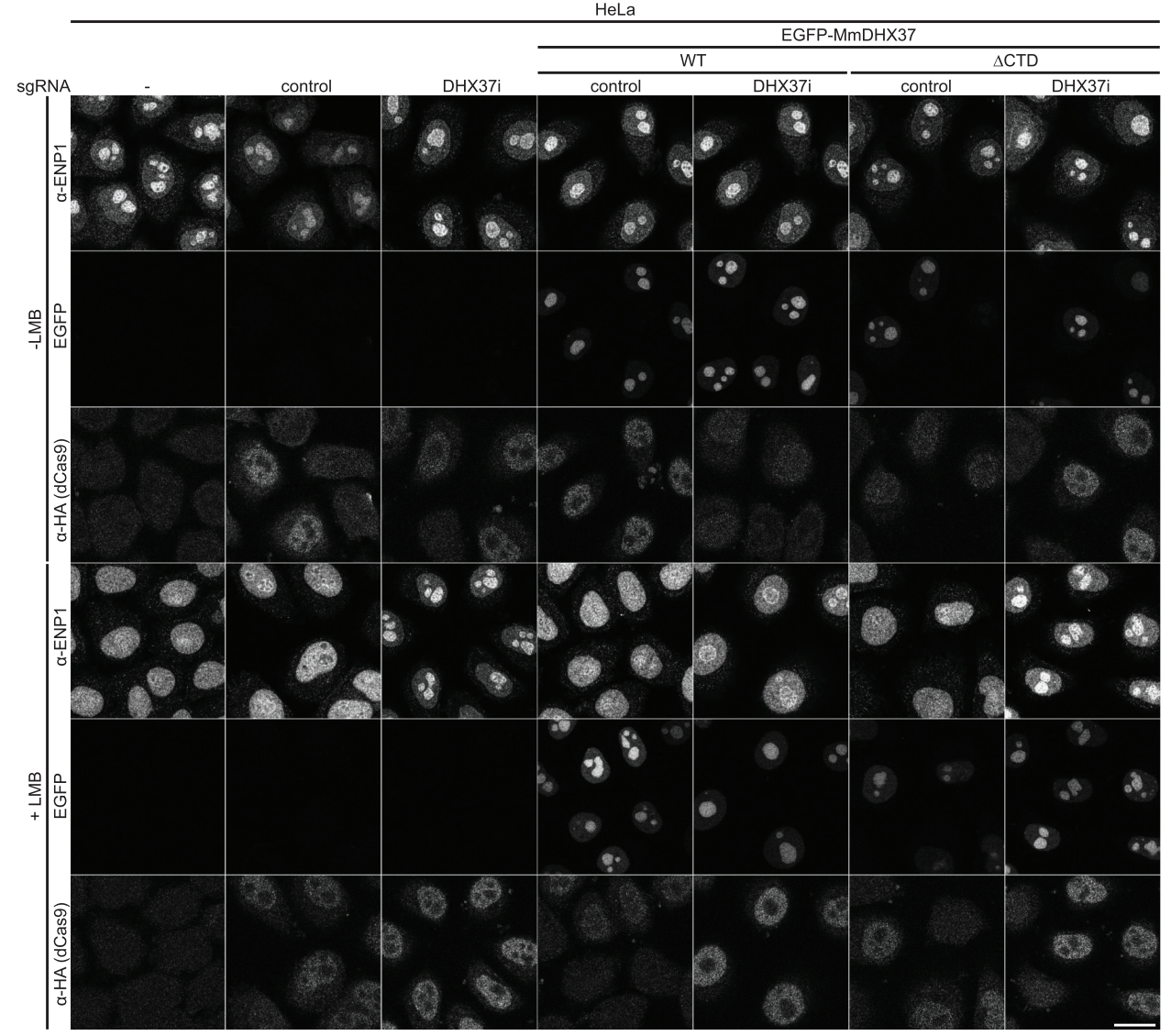

FIGURE 4. The CTD of DHX37 is required for interaction with UTP14A in vitro and for ribosome biogenesis in vivo. (A) Pull-down experiment using recombinant maltose-binding protein-tagged UTP14A ${ }^{\min }$ and full-length and $\triangle \mathrm{CTD}$ MmDHX37 expressed in HEK293 cells. (B) Immunofluorescence analysis of the localization of the 40S subunit assembly factor ENP1 in HeLa cells expressing wild-type EGFPMmDHX37, a truncated version lacking the carboxy-terminal domain ( $\triangle \mathrm{CTD}$ ), or the ATPase-deficient E3690 mutant. Expression of DHX37 proteins was induced with tetracycline for $24 \mathrm{~h}$. Ninety minutes before fixation, cells were either supplemented with a solvent control or with $20 \mathrm{nM}$ leptomycin B (LMB) to prevent CRM1-dependent nuclear export, leading to nucleoplasmic accumulation of ENP1 along with newly made 40S subunits in control cells (Badertscher et al. 2015). Note that the E369Q mutant prevents relocalization of ENP1 to the nucleoplasm in the presence of LMB, indicative of early 40 S subunit maturation defects. (C) The CTD of DHX37 is required to rescue early 40 S biogenesis defects upon DHX37 depletion. DHX37 was depleted from HeLa cells by CRISPRi. HeLa cells were left untreated (-) or transfected for $72 \mathrm{~h}$ with a plasmid encoding HA-tagged dCas9 and either a sgRNA targeting endogenous DHX37 (DHX37i) or a control sgRNA and transfected cells were selected with puromycin. Expression of the indicated EGFP-MmDHX37 rescue constructs was induced for $24 \mathrm{~h}$ with tetracycline. Cells were treated with LMB for 90 min before fixation as indicated. The expression of HA-tagged dCas9 and localization of the 40S assembly factor ENP1 were analyzed by immunofluorescence. Scale bars, $20 \mu \mathrm{M}$. 
recruited to the maturing 405 subunit in part by interactions with UTP14A and its ATP-dependent helicase activity is subsequently activated by UTP14A to promote the removal of U3 snoRNA, which triggers pre-18S rRNA folding and is required for ITS1 cleavage. In light of the results of the overexpression and rescue experiments, we conclude that the CTD of DHX37 is critical for this process. As with Dhr1 in yeast (Granneman et al. 2006; Sardana et al. 2015), overexpression of ATPase-deficient DHX37 inhibits $40 \mathrm{~S}$ biogenesis, presumably because the helicase can still be recruited to the preribosomal particle but is unable to catalyze the removal of U3 snoRNA. Since DHX37 lacking the CTD is unable to exert the dominant-negative effect on $40 S$ biogenesis, yet fails to rescue the phenotype caused by DHX37 depletion, our interpretation is that the CTD is required for UTP14A-dependent recruitment and activation of the helicase.

\section{Conclusions}

RNA helicases, including DHX37/Dhr1, play indispensable roles in ribosome biogenesis. In this study, we determined the crystal structure of the DHX37-RNA complex in the nucleotide-exchange state, providing insights into the molecular mechanism for the ATP-dependent RNA translocation activity of DHX37 required for U3 snoRNA removal during $40 \mathrm{~S}$ subunit maturation. Comparisons with structures of DHX36 and Prp43 in their respective nucleotide-free and the ATP-bound states suggest that ATP binding induces DHX37 to convert from an open conformation, in which a 5-nt RNA segment is accommodated in the RNA binding channel, to a closed conformation in which a 4-nt RNA segment is bound (Supplemental Fig. S7). Our structural insights thus lend further support to a mechanistic model for DEAH helicases in which conformational cycling between ATP-bound and nucleotide-free states results in directional $3^{\prime}$ to $5^{\prime}$ translocation along single-stranded RNA, which is coupled to RNA duplex unwinding or RNP remodeling.

Recent studies have suggested that UTP14A functions as a ribosome biogenesis factor in part by recruiting $\mathrm{DHX} 37$ to the maturing preribosomal particle (Choudhury et al. 2018). Our biochemical experiments reveal that a conserved motif in UTP14A, distinct from the canonical $\mathrm{DEAH}$-interacting motif found in $\mathrm{G}$-patch proteins, is necessary and sufficient for interaction with DHX37. The motif is part of the central region of UTP14A that is likely to be exposed on the surface of the SSU processome, poised to mediate DHX37 recruitment. In turn, interaction with UTP14A is mediated in part by the structurally unique CTD in DHX37, which is also required for ribosome biogenesis. Finally, our work suggests that UTP14A stimulates the activity of DHX37 by acting as a processivity factor that enhances RNA binding and the coupling between ATPase and RNA translocase/remodeling activities. Together, these insights provide a mechanistic rationale for the coordination of DHX37 recruitment and activation in driving a key step in 405 subunit maturation and have implications for other DEAH helicases involved in ribosome biogenesis, such as Prp43. Determining the structural basis of the UTP14A-DHX37 interaction will be an important future step toward understanding the regulation of not only DHX37 but DEAH helicases in general.

\section{MATERIALS AND METHODS}

\section{Protein expression and purification}

All constructs used were cloned into MacroLab vectors developed by Scott Gradia (University of California, Berkeley) using ligationindependent cloning. Full-length murine DHX37 (MmDHX37) and an amino-terminally truncated fragment of murine DHX37 encompassing residues $179-1150\left(\mathrm{MmDHX} 37^{179-1150}\right)$ were inserted into the MacroLab vector 438B (Addgene \#55219), in frame with an amino-terminal $\mathrm{His}_{6}$-tag cleavable using Tobacco Etch Virus (TEV) protease. Full-length human UTP14A (HsUTP14A) was inserted into the 438Rgfp vector (Addgene \#55221) in frame with an amino-terminal (Strepll)-GFP-tag. The 438Rgfp-HsUTP14A construct was combined with 438B-MmDHX37 $7^{179-1150}$ into a single plasmid for subsequent coexpression in insect cells and copurification (Gradia et al. 2017). An amino-terminally truncated fragment of murine DHX37 encompassing residues 139-1150 $\left(\mathrm{MmDHX} 37^{139-1150}\right)$ was inserted into a modified 5B vector (Addgene \#30122) with an amino-terminal His 6 -(Strepll) -tag. $_{2}$. The CTD of murine DHX37, encompassing residues 1003-1150 (MmDHX37 ${ }^{\mathrm{CTD}}$ ), was inserted into MacroLab vector 2G-T (Addgene \#29707) in fusion with an amino-terminal His 6 -GSTtag. A truncated construct of human HsUTP14A encompassing residues 555-619 (HsUTP14A ${ }^{\mathrm{min}}$ ) was inserted into MacroLab vector $1 \mathrm{M}$ (Addgene \#29656) in fusion with an amino-terminal $\mathrm{His}_{6}$-MBP-tag. All DHX37 constructs, except MmDHX37 were expressed in Sf9 insect cells using the Bac-to-Bac system (Invitrogen) according to standard protocols. Briefly, Sf9 insect cells were infected with $\mathrm{P} 3$ virus $(2.5 \mathrm{~mL}$ per $0.5 \mathrm{~L}$ ) at a density of $1.0 \times 10^{6} \mathrm{~mL}^{-1}$. Sixty-four hours after infection Sf9 cells were harvested and resuspended in Sf9 lysis buffer $(20 \mathrm{mM}$ Tris $\mathrm{pH} 8.0$, $500 \mathrm{mM} \mathrm{NaCl}, 5 \mathrm{mM}$ imidazole, $0.1 \%$ Tween 20, supplemented with Roche Protease Inhibitor Cocktail; $50 \mathrm{~mL}$ per $1 \mathrm{~L}$ of culture). Cells were lysed for 25 min by sonication ( $20 \%$ amplitude, $3 \mathrm{sec}$ pulse on, $17 \mathrm{sec}$ pulse off, $4^{\circ} \mathrm{C}$ ) and lysates were clarified at $18,000 \mathrm{~g}$ for $30 \mathrm{~min}$ at $4^{\circ} \mathrm{C}$.

Full length $\mathrm{His}_{6}-\mathrm{MmDHX} 37$, $\mathrm{His}_{6}-\mathrm{MmDHX} 37^{179-1150}$, and $\mathrm{His}_{6}-\mathrm{MmDHX} 37^{179-1150} / \mathrm{Strepll-GFP-HsUTP14A}$ complex were purified by Nickel affinity chromatography $\left(\mathrm{Ni}^{2+}-\mathrm{NTA}\right.$-sepharose resin; Qiagen). The column was washed with Ni-wash buffer (20 $\mathrm{mM}$ Tris pH 8.0, $500 \mathrm{mM} \mathrm{NaCl}, 20 \mathrm{mM}$ imidazole) and bound protein was eluted with Ni-elution buffer ( $20 \mathrm{mM}$ Tris $\mathrm{pH} 8.0,150 \mathrm{mM}$

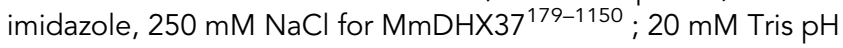
8.0, $150 \mathrm{mM}$ imidazole, $500 \mathrm{mM} \mathrm{NaCl}$ for MmDHX37 and the

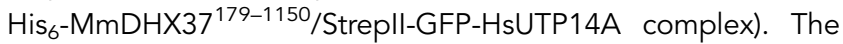
protein was subsequently cleaved with Tobacco Etch Virus (TEV) protease while dialyzed overnight at $4^{\circ} \mathrm{C}$ against $20 \mathrm{mM}$ Tris $\mathrm{pH}$ $7.5,250 \mathrm{mM} \mathrm{NaCl}(500 \mathrm{mM} \mathrm{NaCl}$ for MmDHX37 and complex), 
$1 \mathrm{mM}$ TCEP pH 7.0 [Tris(2-carboxyethyl)phosphine hydrochloride]. In a second Ni-affinity chromatography step uncleaved $\mathrm{His}_{6}$-protein, $\mathrm{His}_{6}$-tagged TEV, and free $\mathrm{His}_{6}$-tag were removed. After the second Ni-affinity step, the $\mathrm{NaCl}$ concentration in the flow-through fraction was reduced to $250 \mathrm{mM}$ using $\mathrm{KO}$ buffer (20 mM Tris pH 7.5, $1 \mathrm{mM} \mathrm{DTT)} \mathrm{if} \mathrm{necessary.} \mathrm{The} \mathrm{cleaved} \mathrm{proteins}$ were subjected to cation exchange chromatography using a Heparin column (HiTrap Heparin, GE Healthcare). The column was washed using IEX buffer A (20 mM Tris $\mathrm{pH} 7.5,100 \mathrm{mM}$ $\mathrm{NaCl}, 1 \mathrm{mM}$ DTT) and protein was eluted by applying a gradient from $0 \%$ to $100 \%$ IEX buffer B (IEX buffer B: $20 \mathrm{mM}$ Tris $\mathrm{pH} 7.5$, $1000 \mathrm{mM} \mathrm{NaCl}, 1 \mathrm{mM}$ DTT) over 20 column volumes. DHX37 was finally purified by a size exclusion chromatography step using a Superdex 200 column and eluted in 20 mM HEPES pH 7.5, 250 $\mathrm{mM} \mathrm{KCl}\left(350 \mathrm{mM} \mathrm{KCl}\right.$ for MmDHX37 and MmDHX37 $7^{179-1150 /}$ HsUTP14A complex), $1 \mathrm{mM}$ DTT. Eluted protein samples were concentrated and flash frozen with liquid nitrogen and stored at $-80^{\circ} \mathrm{C}$.

GST-tagged MmDHX37 ${ }^{\mathrm{CTD}}$ fusion protein was expressed in E. coli Rosetta 2 DE3 cells (Novagen, Merck Millipore) for $4 \mathrm{~h}$ at $37^{\circ} \mathrm{C}$ after induction with $0.2 \mathrm{mM}$ IPTG (Isopropyl- $\beta$-D-thiogalactopyranoside). The protein was resuspended in lysis buffer (15 $\mathrm{mL}$ per $1 \mathrm{~L}$ culture; $20 \mathrm{mM}$ Tris $\mathrm{pH} 8.0,500 \mathrm{mM} \mathrm{NaCl}$, $1 \mathrm{mM}$ DTT) and lysed using a cell homogenizer (HPL6 cell homogenizer; passed three times, $4^{\circ} \mathrm{C}$ ). Cell lysates were clarified at $18,000 \mathrm{~g}$ for $30 \mathrm{~min}$ at $4^{\circ} \mathrm{C}$. GST-tagged $\mathrm{MmDH} \times 37^{\mathrm{CTD}}$ was purified by glutathione (GSH) affinity chromatography. The bound protein was washed with wash buffer $(20 \mathrm{mM}$ Tris $\mathrm{pH}$ 8.0, $500 \mathrm{mM} \mathrm{NaCl}, 1 \mathrm{mM} \mathrm{DTT}$ ) and eluted in lysis buffer supplemented with $10 \mathrm{mM}$ reduced GSH. MmDHX37 ${ }^{\mathrm{CTD}}$ was finally purified by a size exclusion chromatography step using a Superdex 200 column and eluted in $20 \mathrm{mM} \mathrm{HEPES} \mathrm{pH} \mathrm{7.5,} 250 \mathrm{mM} \mathrm{KCl}$, $1 \mathrm{mM}$ DTT. The protein was flash frozen with liquid nitrogen and stored at $-80^{\circ} \mathrm{C}$.

$\mathrm{His}_{6}-(\text { Strepll) })_{2}-\mathrm{MmDHX37} 7^{139-1150}$ was purified by Nickel affinity chromatography as described above and dialyzed overnight at $4^{\circ} \mathrm{C}$ against $20 \mathrm{mM}$ Tris $\mathrm{pH} 7.5,250 \mathrm{mM} \mathrm{NaCl}, 1 \mathrm{mM}$ DTT without tag cleavage. The protein was flash frozen with liquid nitrogen and stored at $-80^{\circ} \mathrm{C}$. Catalytic inactive MmDHX37 $7^{179-1150 \_E 3690}$

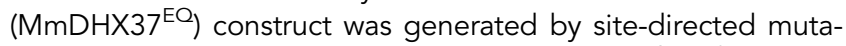
genesis (QuikChange) using 438B-MmDHX37 $7^{179-1150}$ as PCR

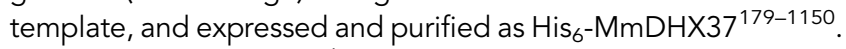

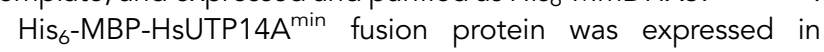
Rosetta 2 DE3 cells (Novagen, Merck Millipore) for $4 \mathrm{~h}$ at $37^{\circ} \mathrm{C}$ after induction with $0.2 \mathrm{mM}$ IPTG. The protein was resuspended in Ni-NTA lysis buffer $(15 \mathrm{~mL}$ per $1 \mathrm{~L}$ culture; $20 \mathrm{mM}$ Tris $\mathrm{pH}$ 8.0, $250 \mathrm{mM} \mathrm{NaCl}, 5 \mathrm{mM}$ imidazole) and lysed using a cell homogenizer (HPL6 cell homogenizer; passed three times, $4^{\circ} \mathrm{C}$ ). Cell lysates were harvested and purified by Ni-NTA affinity chromatography as described above. Before flash freezing, the imidazole concentration of the protein sample was adjusted to $30 \mathrm{mM}$ imidazole. The protein sample was stored at $-80^{\circ} \mathrm{C}$. HsUTP14A alanine substitution mutant constructs, His 6 -MBP-

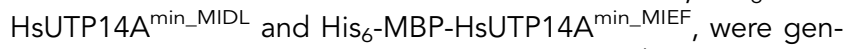
erated using inverse PCR with $1 \mathrm{M}-\mathrm{Hs} U T P 14 \mathrm{~A}^{\mathrm{min}}$ as PCR template, and expressed and purified as $\mathrm{His}_{6}-\mathrm{MBP}-\mathrm{HsUTP}_{14} \mathrm{~A}^{\mathrm{min}}$.

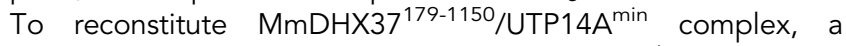

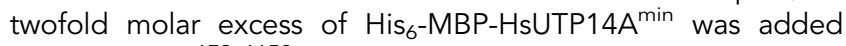
to $\mathrm{MmDHX} 37^{179-1150}$ and incubated at room temperature for $10 \mathrm{~min}$.

\section{Crystallization and data collection}

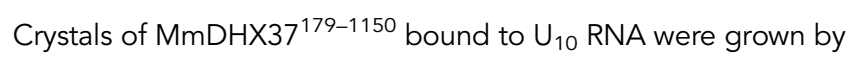
the hanging drop vapor diffusion method by mixing equal volumes $\left(1 \mu \mathrm{L}+1 \mu \mathrm{L}\right.$ ) of $\mathrm{MmDHX} 37^{179-1150}$ (preincubated at a concentration of $7 \mathrm{mg} \mathrm{mL}^{-1}$ with 1.5-fold molar excess of singlestranded $\mathrm{U}_{10} \mathrm{RNA}, 1 \mathrm{mM}$ AMPPNP and $2.5 \mathrm{mM} \mathrm{MgCl}_{2}$ ), and reservoir solution containing $0.1 \mathrm{M}$ Bis-Tris propane $\mathrm{pH} 7.0,0.2 \mathrm{M}$ $\mathrm{NaNO}_{3}, 15 \%$ (w/v) polyethylene glycol (PEG) 3400 and incubation at $20^{\circ} \mathrm{C}$. The size and morphology of crystals was optimized by microseeding. Au-derivatized crystals were obtained by soaking native crystals for $15 \mathrm{~min}$ in mother liquor supplemented with $10 \mathrm{mM} \mathrm{K}\left[\mathrm{Au}(\mathrm{CN})_{2}\right]$. Before flash cooling in liquid nitrogen, crystals were cryoprotected by brief soaking in mother liquor supplemented with $15 \%(v / v)$ ethylene glycol. X-ray diffraction data were collected at beamline X06DA (PXIII) of the Swiss Light Source (Paul Scherrer Institute, Villigen, Switzerland). The crystals belonged to space group $P 2_{1}$, contained two copies of the DHX37-RNA complex in the asymmetric unit, and diffracted to a resolution of $2.9 \AA$ (native crystal) or $3.0 \AA$ (Au-derivatized crystal). For the Au-derivatized crystal a single-wavelength anomalous diffraction (SAD) experiment was performed. From a single crystal, seven $360^{\circ}$ data sets were measured at a wavelength of 1.03980 $\AA$, which corresponds to the Au L-III absorption edge. The diffraction data were processed using XDS (Kabsch 2010). SAD data was additionally scaled and merged with XSCALE (Kabsch 2010).

\section{Structure determination, refinement, and analysis}

Structure determination was performed with the Phenix suite (Adams et al. 2010) based on the SAD data obtained from the Au-derivatized crystal. Twenty-seven Au sites were identified using phenix.hyss. Substructure refinement, phasing and density modification in phenix.autosol (Zwart et al. 2008) resulted in a clearly interpretable experimental electron density map, which was used for manual model building with COOT (Emsley and Cowtan 2004). The majority of DHX37 residues as well as uridine ribonucleotides could be assigned and built into the experimental electron density map. Next, molecular replacement was performed with the high-resolution native data set using phenix. phaser (McCoy et al. 2007). Structure refinement was carried out with phenix.refine (Afonine et al. 2012). For the initial refinement round, the B-factors of the starting model were set to $40 \AA^{2}$. The initial round of refinement included rigid-body refinement, atomic coordinate refinement, and individual B-factor refinement. This was followed by iterative rounds of atomic coordinate, TLS and individual B-factor refinement, alternated with manual building in COOT to complete the atomic model. Noncrystallographic symmetry restraints were applied throughout the refinement and only released in the final round. The final atomic model was refined at a resolution of $2.9 \AA$ with an $R_{\text {free }}$ of $29.7 \%$ and an $R_{\text {work }}$ of $26.8 \%$. X-ray crystallographic data collection and refinement parameters are provided in Table 2. The final model of the DHX37- $U_{10}$ complex comprises 10 uridine ribonucleotides and DHX37 amino acid residues 231-1149, except for residues 432 and 490-578, which are disordered in electron density maps. Analysis of the two MmDHX37 $7^{179-1150}$ molecules using 
TABLE 2. Data collection and refinement statistics

\begin{tabular}{|c|c|c|}
\hline \multirow[b]{2}{*}{ Data set } & \multicolumn{2}{|c|}{ DHX37 } \\
\hline & Native & $\mathrm{Hg}$ SAD \\
\hline X-ray source & SLS X06DA (PXIII) & SLS X06DA (PXIII) \\
\hline Space group & $P 2_{1}$ & $P 2_{1}$ \\
\hline \multicolumn{3}{|l|}{ Cell dimensions } \\
\hline$a, b, c(\AA)$ & $83.83,137.60,94.23$ & $83.69,138.16,94.89$ \\
\hline$\alpha, \beta, \gamma\left({ }^{\circ}\right)$ & $90.00,93.34,90.00$ & $90.00,93.67,90.00$ \\
\hline Wavelength $(\AA ̊)$ & 1.0077 & 1.0398 \\
\hline Resolution $(\AA ̊)^{a}$ & $47.03-2.88(2.98-2.88)$ & $45.61-2.99(3.10-2.99)$ \\
\hline$R_{\text {merge }}{ }^{a}$ & $0.112(0.684)$ & $0.186(2.054)$ \\
\hline $\mathrm{CC}_{1 / 2}{ }^{\mathrm{a}}$ & $0.996(0.746)$ & $0.999(0.761)$ \\
\hline$|/ \sigma|^{a}$ & $13.65(2.17)$ & $29.47(3.04)$ \\
\hline Observations $^{a}$ & $320,411(25,685)$ & $2,381,443(213,156)$ \\
\hline Unique reflections ${ }^{a}$ & $47,756(4209)$ & $43,382(4240)$ \\
\hline Multiplicity ${ }^{a}$ & $6.7(6.1)$ & $54.9(50.3)$ \\
\hline Completeness (\%) & $98.52(87.65)$ & 99.78 (98.38) \\
\hline \multicolumn{3}{|l|}{ Refinement } \\
\hline Resolution (Å) & $47.03-2.88$ & \\
\hline No. reflections & 47,734 (4209) & \\
\hline$R_{\text {work }} / R_{\text {free }}$ & $0.270 / 0.295$ & \\
\hline \multicolumn{3}{|l|}{ No. atoms } \\
\hline Protein & 12,605 & \\
\hline RNA & 394 & \\
\hline \multicolumn{3}{|l|}{ B-factors $\left(\AA^{2}\right)$} \\
\hline Mean & 65.3 & \\
\hline Protein & 65.2 & \\
\hline RNA & 68.2 & \\
\hline \multicolumn{3}{|l|}{ R.m.s. deviations } \\
\hline Bond lengths ( $\AA$ ) & 0.005 & \\
\hline Bond angles $\left({ }^{\circ}\right)$ & 0.79 & \\
\hline \multicolumn{3}{|l|}{ Ramachandran plot } \\
\hline$\%$ Favored & 96.8 & \\
\hline$\%$ Allowed & 3.2 & \\
\hline$\%$ Outliers & 0.0 & \\
\hline
\end{tabular}

avalues in parentheses denote highest resolution shell.

DynDom (Hayward et al. 1997) indicates that the major conformational difference between the two copies in the asymmetric unit involves a rotation by $8.8^{\circ}$ of the CTD relative to the helicase core (comprising domains RecA1, RecA2, HA2, and OB) about a pivot point centered on residues 1007-1008. The helicase cores of the two DHX37 $7^{179-1150}$ copies superimpose as rigid bodies and align with an RMSD of $1.03 \AA$ over $659 \mathrm{C} \alpha$ atoms. The CTD domains superimpose with an RMSD of $0.45 \AA$ over $127 \mathrm{C} \alpha$ atoms. Structure superpositions of DHX37 and Prp43 and DHX36 were performed using the DALI server (Holm and Sander 1995). To model the conformation of MmDHX37 in the activated ATPand RNA-bound state (MmDHX37-ATP-RNA complex), individual DHX37 domains (as defined in Fig. 1A), except for the CTD, were individually superimposed with the structure of the crPrp43-RNA-ADP.BeF ${ }_{3}^{-}$complex (Tauchert et al. 2017) and combined in a single-polypeptide model. Domain motions predicted to occur during the RNA translocation cycle were subsequently analysed by comparing the resulting model with the crystal structure of the nucleotide-free MmDHX37-RNA complex in DynDom.

\section{ATPase activity assays}

The ATPase activities of DHX37 constructs in the presence and absence of UTP14A were measured using the EnzCheck 
Phosphate kit (Invitrogen) at $26^{\circ} \mathrm{C}$. Here, the provided 2-amino-6mercapto-7-methylpurine riboside (MESG) substrate together with the released inorganic phosphate $\left(P_{i}\right)$ is enzymatically converted to 2-amino-6-mercapto-7-methyl-purine which absorbs light at $360 \mathrm{~nm}$, thus, facilitating the measurement of the $P_{i}$ concentration in the reaction mixture. All reactions were performed in triplicates in a buffer containing $50 \mathrm{mM}$ HEPES pH 7.5, $150 \mathrm{mM}$ $\mathrm{KCl}, 1 \mathrm{mM} \mathrm{DTT}$, and $1 \mathrm{mM} \mathrm{MgCl}$, in a total volume of $200 \mu \mathrm{L}$. For ATPase activity assays (Supplemental Figs. S1A, S9B,D, S11A) 0. $25 \mu \mathrm{M}$ DHX37 (and complexes) was used. For reactions carried out in the presence of RNA, $0.25 \mu \mathrm{M}$ single-stranded $U_{10}$ RNA was added to the protein samples, and the samples were incubated for $10 \mathrm{~min}$ at room temperature. Reactions were supplemented with $0.2 \mathrm{U}$ purine nucleoside phosphorylase (PNP) and $1 \mathrm{mM}$ MESG according to the manufacturers protocol. The ATPase reactions were initiated by adding ATP and $\mathrm{MgCl}_{2}$ (both at $2 \mathrm{mM}$ final concentration) to the samples. Absorbance at $360 \mathrm{~nm}$ was measured once per minute over $40 \mathrm{~min}$ in a microplate reader (PheraStar FSX fluorescence plate reader; BMG Labtech). The absorbance values at $360 \mathrm{~nm}$ were corrected for background absorbance. To quantify the released $\mathrm{P}_{\mathrm{i}}$, a calibration curve was generated with the phosphate standard provided together with the kit. The resulting values were plotted as a function of time using the GraphPad Prism software. To compare ATPase activities between samples, data points within the linear range were fitted with linear regression, and listed in Supplemental Table S1. The data represent mean values from three replicates, while the error bars indicate the standard error.

For Michaelis-Menten analysis (Fig. 3C), MmDHX37 $7^{179-1150}$ was used at final concentrations of $2 \mu \mathrm{M}$ in the absence of RNA or $1 \mu \mathrm{M}$ when assayed in the presence of $U_{10}$ RNA. The

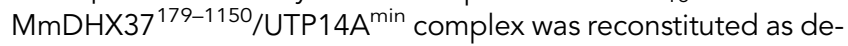
scribed above and assayed at a final concentration of $0.125 \mu \mathrm{M}$. For experiments carried out in the presence of RNA, a 1.5-fold molar excess of $U_{10}$ RNA was added. ATP was used at concentrations of 7.8125-1000 $\mu \mathrm{M}$. ATPase activities were normalized for DHX37 concentrations to allow direct comparisons. The data represent mean values from three replicates, while the error bars indicate the standard error. $K_{\mathrm{M}}$ and $k_{\text {cat }}$ values were fitted according to the Michaelis-Menten equation in GraphPad Prism and are provided in Table 1.

To investigate the effect of RNA on ATPase activity (Fig. 3D),

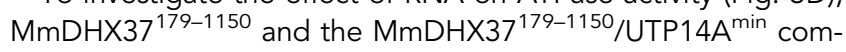
plex were used at a final concentration of $0.5 \mu \mathrm{M}$, ATP at a final concentration of $1 \mathrm{mM}$, and $U_{10}$ RNA was titrated to final concentrations of 0.1-12.8 $\mu \mathrm{M}$. Absorbance values at $360 \mathrm{~nm}$ were recorded every $15 \mathrm{sec}$ for $25 \mathrm{~min}$ and quantified using the phosphate standard as described above. Initial reaction rates were calculated from the linear region of the absorbance curve. The resulting values were plotted as a function of ATP concentration (or RNA concentration) using GraphPad Prism and fitted by nonlinear regression analysis using the dose-versus-response relationship to calculate half-maximal effective concentration $\left(E_{50}\right)$ values.

\section{Equilibrium RNA binding experiments}

RNA binding affinities of DHX37 in the presence and absence of UTP14A were determined by FP measurements with $5^{\prime}$ -
ATTO532-labeled $\mathrm{U}_{12}$ RNA at $26^{\circ} \mathrm{C}$ using a PheraStar FSX fluorescence plate reader. All reactions were carried out in triplicates in a buffer containing $20 \mathrm{mM}$ HEPES $\mathrm{pH}$ 7.5, $150 \mathrm{mM} \mathrm{KCl}, 2 \mathrm{mM}$ $\mathrm{MgCl}_{2}$, and $0.1 \%$ Tween20, in a total volume of $50 \mu \mathrm{L} . \mathrm{NaCl}$, $\mathrm{MgCl}_{2}$, and Tween20 concentrations of the protein samples were adjusted to $150 \mathrm{mM}, 2 \mathrm{mM}$, and $0.1 \%$ Tween 20 , respectively, using 1.5x K50 buffer (20 mM HEPES pH 7.5, 50 mM KCl, 3 mM

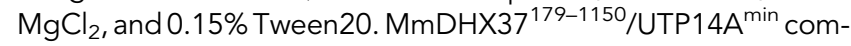
plex was reconstituted as described above. For the RNA binding measurements, $0.25 \mathrm{nM}$ Atto ${ }^{532}$-labeled $\mathrm{U}_{12}$ RNA were titrated

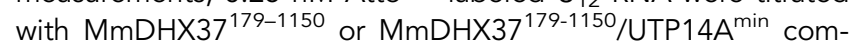
plex at varying concentrations ranging from $0.27 \mathrm{nM}$ to $17.5 \mu \mathrm{M}$. For measurements performed in the presence of adenosine nucleotides, ADP and AMPPNP were added at final concentrations of 1 $\mathrm{mM}$. The AMPPNP stock (Jena Bioscience) was analysed by HPLC prior to its usage and estimated to be $>95 \%$ pure. Fluorescence polarization (FP) signal was measured with an excitation filter with a central wavelength of $540 \mathrm{~nm}$, and $P$ and $S$ emission filters with a central wavelength of $590 \mathrm{~nm}$. The resulting FP values were plotted using the Graphpad Prism software as a function of concentration and fitted to a modified one-site binding equation accounting for ligand depletion:

$$
Y=i+\left((a-i) \cdot \frac{(c+K+X)-\sqrt{ }\left((-c-X-K)^{2}-4 c X\right)}{2 c}\right)
$$

where $K$ is the $K_{d}$ to be determined, $c$ is the total concentration of Atto532-labeled RNA, $i$ is the Ymin value, and $a$ is the Ymax value. The polarization amplitudes were normalized to 1. Error bars indicate standard errors of the mean (SEM) for five consecutive measurements of a single representative sample. The calculated $K_{d}$ values are provided in Table 1.

\section{RNA pull-down experiment}

For the RNA binding assay, $3 \mu \mathrm{g}$ of $\mathrm{MmDHX} 37^{179-1150}$ were incubated in binding buffer (20 mM HEPES pH 7.5, $150 \mathrm{mM} \mathrm{KCl}$, $2 \mathrm{mM} \mathrm{MgCl}_{2}, 0.1 \%$ Tween20, $1 \mathrm{mM} \mathrm{DTT}$ ) in the presence or absence of $1 \mathrm{mM}$ adenosine nucleotides (AMPPNP or ADP) and $333 \mathrm{nM} 5^{\prime}$ end biotinylated $U_{20}$ single-stranded RNA in a volume of $30 \mu \mathrm{L}$. After $60 \mathrm{~min}$ incubation at $4^{\circ} \mathrm{C}, 50 \mu \mathrm{L}$ magnetic streptavidin coupled beads (Streptavidin-coupled Dynabeads, ThermoScientific) and $200 \mu \mathrm{L}$ of binding buffer (supplemented with or without $1 \mathrm{mM}$ AMPPNP and ADP) were added. The samples were incubated with the beads for $1 \mathrm{~h}$ at $4^{\circ} \mathrm{C}$. Beads were washed three times with $0.5 \mathrm{~mL}$ binding buffer and samples were eluted in SDS dye. Analysis of the eluted samples was done by SDS-PAGE.

\section{DHX37-UTP14A pull-down experiments}

HEK293T cells were grown in DMEM supplemented with $10 \%$ fetal bovine serum, $100 \mathrm{U} \mathrm{mL}^{-1}$ penicillin/streptomycin (Sigma), 2 $\mathrm{mM}$ L-glutamine (Sigma) and $100 \mu \mathrm{g} \mathrm{mL}^{-1}$ sodium pyruvate at $37^{\circ} \mathrm{C}$ and $5 \% \mathrm{CO}_{2}$. For overexpression in mammalian HEK293T cells, full-length HsUTP14A and truncations were PCR amplified and were cloned into a homemade plasmid based on the ligation-independent MacroLab vector 6A (Addgene \#30124), 
adding an amino-terminal $\mathrm{His}_{6}-\left(\mathrm{HA}_{3}\right)_{3}$-mCherry-tag. $\mathrm{HsUTP}_{14 \mathrm{~A}^{\text {min }}}$ multi-alanine binding mutants M558A/I559A/D560A/L561A, (HsUTP14A ${ }^{\text {min_MIDL) }}$ and M594A/I595A/E597A/F599A (HsUT P14A ${ }^{\text {min_MIEF })}$ constructs were generated by inverse PCR. Transfections were performed in 10-cm dishes seeded with $2 \times$ $10^{6}$ cells using the X-tremeGENE HP DNA Transfection Reagent (Roche) and 3-4.5 $\mathrm{\mu g}$ plasmid DNA per transfection. HEK293T cells were collected $48 \mathrm{~h}$ post-transfection, washed twice with PBS and resuspended in $1.5 \mathrm{~mL}$ assay buffer $(20 \mathrm{mM}$ Tris $\mathrm{pH}$ 7.5, $150 \mathrm{mM} \mathrm{KCl}, 1 \mathrm{mM}$ EDTA, 0.1\% [v/v] Tween20, 1 mM DTT) supplemented with Roche Protease Inhibitor Cocktail. The cells were detached by gentle rocking at $4^{\circ} \mathrm{C}$ for $10 \mathrm{~min}$ and lysed by sonication ( $10 \%$ amplitude, $0.5 \mathrm{sec}$ pulse on, $2 \mathrm{sec}$ pulse off, 15 times, $4^{\circ} \mathrm{C}$ ). The lysates were cleared by two centrifugation steps at 14,000 rpm for $15 \mathrm{~min}$ and incubated with $5 \mu \mathrm{g} / \mathrm{mL}$ RNAse A (Thermo Fisher) for 20 min on ice. Per reaction, $25 \mu \mathrm{L}$ (packed volume) Strep-Tactin Sepharose beads (IBA) were incubated with $250 \mu \mathrm{g}$ of $\mathrm{His}_{6}$-(StreplI)-MmDHX37 ${ }^{139-1150}$ for $30 \mathrm{~min}$ at $4{ }^{\circ} \mathrm{C}$ and washed three times with HEK assay buffer. For the pull-downs, $450 \mu \mathrm{L}$ of cleared HEK293T cell lysates were incubated with $25 \mu \mathrm{L} \mathrm{MmDHX37-Strep-beads} \mathrm{for} 1 \mathrm{~h}$ at $4^{\circ} \mathrm{C}$. For the no bait control, $25 \mu \mathrm{L}$ Strep-beads without MmDHX37 were incubated with $450 \mu \mathrm{L}$ HEK293T cell lysate. The beads were washed four times with HEK293T assay buffer and bound proteins were eluted in two 10 min-steps on ice with $15 \mu \mathrm{L}$ elution buffer $(20 \mathrm{mM}$ Tris $\mathrm{pH} 8.0,150 \mathrm{mM} \mathrm{KCl}, 1 \mathrm{mM}$ EDTA, $2.5 \mathrm{mM}$ desthiobiotin) each. The eluted samples and the input lysate were loaded on SDS-PAGE without prior boiling to avoid mCherry denaturation, visualized on a Typhoon FLA9500 fluorescence scanner (GE Healthcare) and subsequently stained with Coomassie brilliant blue R250.

For MBP pull-down experiments, $10 \mu \mathrm{g}$ of MBP-tagged UTP14A ${ }^{\text {min }}$ were immobilized on $50 \mu \mathrm{L}$ ( $50 \%$ slurry) of amylose resin (NEB) in a binding buffer containing $20 \mathrm{mM}$ Tris $\mathrm{pH} 7.5,150 \mathrm{mM}$ $\mathrm{KCl}, 1 \mathrm{mM}$ DTT and $0.1 \%$ Tween 20 . The beads were washed and incubated with $15 \mu \mathrm{g}$ of GST-tagged MmDHX37 ${ }^{\text {CTD }}$ in binding buffer for $1 \mathrm{~h}$ at $4^{\circ} \mathrm{C}$ with gentle rocking. Subsequently the beads were washed four times with $1 \mathrm{~mL}$ of binding buffer and proteins were eluted by boiling the resin with $20 \mu \mathrm{L}$ of SDS-PAGE sample buffer. Proteins were analyzed by SDS-PAGE and visualized by Coomassie staining. For GST pull-down experiments, $10 \mu \mathrm{g}$ of GST-tagged $\mathrm{MmDHX37^{ \textrm {CTD } }}$ were immobilized on $50 \mu \mathrm{L}(50 \%$ slurry) of glutathione resin (GE Healthcare) in binding buffer. The beads were washed and incubated with $15 \mu \mathrm{g}$ of MBP-tagged HsUTP $14 A^{555-619}$ in binding buffer for $1 \mathrm{~h}$ at $4{ }^{\circ} \mathrm{C}$ with gentle rocking. The beads were washed four times with $1 \mathrm{~mL}$ of binding buffer and proteins were eluted by boiling the resin with $20 \mu \mathrm{L}$ of SDSPAGE sample buffer. Proteins were analyzed by SDS-PAGE and visualized by Coomassie staining.

\section{DHX37 plasmid constructs for mammalian cell expression}

For expression in mammalian cells (HEK293 and HeLa Flpln TREx cells), full-length MmDHX37 and MmDHX37 encompassing residues 2-1003 ( $\mathrm{MmDHX37^{ \triangle CTD } )}$ were PCR-amplified and subcloned into a modified pcDNA5/FRT/TO expression vector, adding an amino-terminal EGFP-tag (EGFP-MmDHX37 ${ }^{\mathrm{WT}}$ and EGFP-MmDHX37 ${ }^{\triangle C T D}$ ) or an amino-terminal HA-(Strep) $)_{2}$-tag
(HASt-MmDHX37 ${ }^{\triangle C T D}$ ). The EGFP fragment was inserted into the $\mathrm{Kpnl} / \mathrm{HindlII}$ sites of $\mathrm{pcDNA} 5^{\mathrm{TM}} / \mathrm{FRT} / \mathrm{TO}$ (Invitrogen). Catalytically inactive $\mathrm{MmDHX37}$ was generated by PCR using EGFP-MmDHX37 ${ }^{\mathrm{WT}}$ as PCR template (EGFP-MmDHX37 ${ }^{\mathrm{EQ}}$ ).

\section{DHX37 ${ }^{\Delta C T D}$ _UTP14A pull-down experiments}

Transfections of HEK293T cells were performed as described above. Briefly, $3 \mathrm{\mu g}$ plasmid DNA (EGFP-MmDHX37 ${ }^{\mathrm{wt}}$ and EGFP-MmDHX37 ${ }^{\triangle C T D}$ ) were transfected in HEK293T cells at a density of $2 \times 10^{6}$ cells using $9 \mu \mathrm{L}$ of the X-tremeGENE HP DNA Transfection Reagent (Roche). Forty-eight hours posttransfections, cells were harvested and lysed in $1.5 \mathrm{~mL}$ assay buffer (20 mM Tris $\mathrm{pH} 7.5,150 \mathrm{mM} \mathrm{KCl}, 1 \mathrm{mM}$ EDTA, 0.1\% [v/v] Tween20, $1 \mathrm{mM}$ DTT) supplemented with Roche Protease Inhibitor Cocktail, in the presence of RNAse A (Thermo Fisher). Per reaction, $50 \mu \mathrm{L}$ (packed volume) Amylose beads (NEB) were incubated with $2 \mathrm{mg}$ of recombinant $\mathrm{His}_{6}-\mathrm{MBP}-\mathrm{HsUTP}_{14 \mathrm{~A}^{\mathrm{min}}}$ for $30 \mathrm{~min}$ at $4^{\circ} \mathrm{C}$ and washed three times with HEK assay buffer. For the pull-downs, $500 \mu \mathrm{L}$ of cleared HEK293T cell lysates were incubated with $50 \mu \mathrm{L}$ His $_{6}-M B P-H s U T P 14 A^{\text {min }}$-Amylose-beads for $1 \mathrm{~h}$ at $4^{\circ} \mathrm{C}$. For the no bait control, $50 \mu \mathrm{L}$ Amylose-beads without His 6 -MBP-HsUTP14A ${ }^{555-619}$ were incubated with $500 \mu \mathrm{L}$ HEK293T cell lysate. The beads were washed four times with HEK293T assay buffer and bound proteins were eluted in $1 \times$ SDS-PAGE sample loading dye supplemented with $10 \mathrm{mM}$ maltose. Proteins were separated by SDS-PAGE with no prior boiling to avoid EGFP denaturation, visualized on a Typhoon FLA9500 fluorescence scanner (GE Healthcare) and subsequently stained with Coomassie brilliant blue R250.

\section{Expression and purification of DHX37 ${ }^{\triangle C T D}$}

HASt-MmDHX37 ${ }^{\text {CTD }}$ was expressed in suspension-adapted HEK293S-GnTI- cells (ATCC CRL-3022). Cells were grown in HyClone TransFx-H media (Sigma) supplemented with $2 \mathrm{mM}$ L-glutamine (Sigma), $100 \mathrm{U} \mathrm{\textrm {mL } ^ { - 1 }}$ penicillin/streptomycin (Sigma), 1\% FBS (Sigma), and 1\% Pluornic F-68 (Thermo Fisher) at $37^{\circ} \mathrm{C}$ and $5 \% \mathrm{CO}_{2}$ while shaking at $185 \mathrm{rpm}$ in TubeSpin Bioreactor 600 vessels. One day prior to transfection, cells were diluted to a density of $0.7 \times 10^{6}$ cells $\mathrm{mL}^{-1}$. Transfection mix was prepared by diluting plasmid DNA $\left(1.3 \mu \mathrm{g}\right.$ DNA per $\left.10^{6} \mathrm{cells}\right)$ to $0.015 \mu \mathrm{g} \mathrm{LL}^{-1}$ in DMEM media, and mixing it with $25 \mathrm{kDa}$ linear polyethylenimine (PEI, Polysciences) at a concentration of $0.38 \mu \mathrm{g}$ $\mu \mathrm{L}^{-1}$. After incubation for $10 \mathrm{~min}$, the DNA-PEI complexes were diluted 10-fold into the cultured cells, and valproic acid (Sigma) was added to a final concentration of $3 \mathrm{mM}$. Forty-five hours posttransfection, cells were harvested by centrifugation at $500 \mathrm{~g}$ for $10 \mathrm{~min}$ and washed with PBS. The cells were resuspended in lysis buffer $(20 \mathrm{mM}$ Tris $\mathrm{pH}$ 7.5, $350 \mathrm{mM} \mathrm{KCl}, 1 \mathrm{mM}$ DTT, $0.05 \%$ Tween20, supplemented with Roche Protease Inhibitor Cocktail; $100 \mathrm{~mL}$ per $1 \mathrm{~L}$ of culture). Cells were lysed for $30 \mathrm{~min}$ by sonication ( $20 \%$ amplitude, $3 \mathrm{sec}$ pulse on, $17 \mathrm{sec}$ pulse off, $4^{\circ} \mathrm{C}$ ) and lysates were clarified at $18,000 \mathrm{~g}$ for $30 \mathrm{~min}$ at $4^{\circ} \mathrm{C}$. HASt-MmDHX37 ${ }^{\Delta C T D}$ was purified by Strep-Tactin affinity chromatography using $2 \mathrm{~mL}$ of Strep-Tactin resin (Strep-Tactin Superflow; IBA). The bound protein was washed with lysis buffer (20 mM Tris pH 7.5, 350 mM KCl, 1 mM DTT, 0.05\% Tween20) 
and eluted with lysis buffer supplemented with $2.5 \mathrm{mM}$ desthiobiotin.

\section{DHX37 overexpression experiments}

HeLa Flpln TREx cells (kind gift from Dr. M. Beck, EMBL, Heidelberg) were grown in DMEM containing $10 \%$ fetal bovine serum supplemented with penicillin/streptomycin at $37^{\circ} \mathrm{C}$ and $5 \% \mathrm{CO}_{2}$. Monoclonal $\mathrm{HeLa}$ cell lines expressing amino-terminally EGFP-tagged WT, $\triangle$ CTD and E3690 MmDHX37 proteins were generated by stable integration of the plasmid DNA constructs into the FRT site. All cell lines were tested negative for mycoplasma using PCR-based testing. Expression of the constructs was induced by the addition of tetracycline for $24 \mathrm{~h}(\mathrm{WT}: 5.6 \mathrm{ng} / \mathrm{mL}$, $\Delta$ CTD: $500 \mathrm{ng} / \mathrm{mL}$, E3690: $16.7 \mathrm{ng} / \mathrm{mL}$ ).

\section{CRISPRi knockdown-rescue experiments}

For CRISPRi-mediated DHX37 depletion, we modified the method originally described by the Weissman laboratory (Gilbert et al. 2014) by adding an additional nuclear localization signal to the catalytically inactive Cas9 ${ }^{\mathrm{D} 10 \mathrm{~A}}$, H840A mutant (dCas9). In brief, KRAB-dCas9 was amplified from pHR-SFFV-KRAB-dCas9-P2AmCherry (kind gift of Dr. J. Weissman; Addgene, \#60954). The resulting PCR product KRAB-dCas9-HA-2xSV40-NLS was cloned into the Agel/Xhol sites of the $\mathrm{pC} 2 \mathrm{P}$ vector (kind gift of Dr. M. Bühler; Friedrich Miescher Institute for Biomedical Research, Basel) containing a puromycin resistance cassette separated by a self-cleaving P2A (porcine teschovirus-12A) site from the upstream dCas 9 fusion protein. Subsequently, the coding sequence for the importin- $\beta$ binding (IBB) domain of importin $\alpha$ (RCH1) was inserted into the Agel/Hindlll-digested vector at the $5^{\prime}$ end of the dCAS9 cassette. A guide RNA targeting the DHX37 gene was inserted into the Bsal-sites of the same vector by primer annealing ( 5 '-caacgGGTGGTCTGGGAACCCACGT-3' and 5'-aaacACGTGGGTTCCCAGACCACCC), allowing sgRNA expression from a U6 promoter. An analogous vector containing a gRNA targeting the Danio rerio tia1/ served as control (Lackner et al. 2015; 5'-caccgGGTATGTCGGGAACCTCTCC-3' and 5'aaacGGAGAGGTTCCCGACATACCc). For CRISPRi rescue experiments, HeLa cell lines were transfected with CRISPRi vectors using the X-tremeGENE 9 transfection reagent (Roche). After $24 \mathrm{~h}$, cells were reseeded and selected for successful transfection by treatment with $2 \mu \mathrm{g} / \mathrm{mL}$ puromycin for $24 \mathrm{~h}$. Puromycin was washed out thoroughly with PBS and expression of the EGFP$\mathrm{MmDHX} 37$ constructs was induced for $24 \mathrm{~h}$. Ninety minutes before fixation, cells were treated with $20 \mathrm{nM}$ leptomycin B (LMB, LC Laboratories) or solvent (ethanol).

\section{Immunoblot and immunofluorescence analysis and confocal microscopy}

For protein analysis, whole cell extracts were prepared by lysis of cells in SDS sample buffer. Samples were analyzed by SDS-PAGE followed by wet-blotting onto PVDF membranes. Signals were detected on an Odyssey imaging system (LI-COR). The antiENP1 antibody has been described previously (Zemp et al. 2009). Commercial antibodies were anti- $\beta$-actin (A1987, Sigma) and anti-DHX37 (ab70778, abcam). Immunofluorescence analysis was performed as described previously (Zemp et al. 2009). Images were acquired at a Zeiss LSM 880 upright microscope with a $63 \times 1.4 \mathrm{NA}$, oil, DIC Plan-Apochromat objective.

\section{DATA DEPOSITION}

Coordinates and structure factors of the MmDHX37-RNA complex structure have been deposited in the Protein Data Bank with the entry code 6016 .

\section{SUPPLEMENTAL MATERIAL}

Supplemental material is available for this article.

\section{ACKNOWLEDGMENTS}

We thank Meitian Wang, Vincent Olieric, and Takashi Tomizaki at the Swiss Light Source (Paul Scherrer Institute, Villigen, Switzerland) for assistance with X-ray diffraction measurements. We thank members of the Jinek group for critical reading of the manuscript and Marcello Clerici for assistance with crystal structure refinement and manuscript preparation. We thank Justin Walter and Raimund Dutzler for assistance with mammalian cell culture. This work was supported by the Swiss National Science Foundation (SNSF) through the National Center for Competence in Research (NCCR) RNA \& Disease by grants to M.J. and U.K. as well as by SNSF grant 31003A_166565 to U.K. M.J. is an International Research Scholar of the Howard Hughes Medical Institute and a Vallee Scholar of the Bert L\&N Kuggie Vallee Foundation.

Author contributions: F.B., J.H., T.B., U.K., and M.J. designed experiments. F.B. expressed and purified DHX37 and UTP14A proteins, performed RNA binding, ATPase and pull-down assays, crystallized the DHX37-RNA complex, and determined its structure, with assistance from M.J. T.B. carried out CTD interaction analysis and ATPase activity assays. L.K. assisted with sample preparation and performed pull-down experiments. J.H. performed CRISPRi and overexpression experiments in HeLa cells. K.B. assisted with sample preparation. L.B. established the CRISPRi knockdown protocol. M.J. and F.B. wrote the manuscript, with input from T.B., J.H., and U.K.

Received November 15, 2018; accepted March 15, 2019.

\section{REFERENCES}

Adams PD, Afonine PV, Bunkóczi G, Chen VB, Davis IW, Echols N, Headd JJ, Hung L-W, Kapral GJ, Grosse-Kunstleve RW, et al. 2010. PHENIX: a comprehensive Python-based system for macromolecular structure solution. Acta Crystallogr D Biol Crystallogr 66: 213-221. doi:10.1107/S0907444909052925

Afonine PV, Grosse-Kunstleve RW, Echols N, Headd JJ, Moriarty NW, Mustyakimov M, Terwilliger TC, Urzhumtsev A, Zwart $\mathrm{PH}$, Adams PD. 2012. Towards automated crystallographic structure refinement with phenix.refine. Acta Crystallogr D Biol Crystallogr 68: 352-367. doi:10.1107/S0907444912001308

Badertscher L, Wild T, Montellese C, Alexander LT, Bammert L, Sarazova M, Stebler M, Csucs G, Mayer TU, Zamboni N, et al. 
2015. Genome-wide RNAi screening identifies protein modules required for $40 \mathrm{~S}$ subunit synthesis in human cells. Cell Rep 13: 2879-2891. doi:10.1016/j.celrep.2015.11.061

Barandun J, Chaker-Margot M, Hunziker M, Molloy KR, Chait BT, Klinge S. 2017. The complete structure of the small-subunit processome. Nat Struct Mol Biol 24: 944-953. doi:10.1038/ nsmb.3472

Beltrame M, Tollervey D. 1992. Identification and functional analysis of two U3 binding sites on yeast pre-ribosomal RNA. EMBO J 11: 1531-1542. doi:10.1002/j.1460-2075.1992.tb05198.x

Black JJ, Wang Z, Goering LM, Johnson AW. 2018. Utp14 interaction with the small subunit processome. RNA 24: 1214-1228. doi:10 $.1261 /$ rna.066373.118

Büttner K, Nehring S, Hopfner K-P. 2007. Structural basis for DNA duplex separation by a superfamily-2 helicase. Nat Struct Mol Biol 14: 647-652. doi:10.1038/nsmb1246

Chen Y-L, Capeyrou R, Humbert O, Mouffok S, Kadri YA, Lebaron S, Henras AK, Henry Y. 2014. The telomerase inhibitor Gno1p/ PINX1 activates the helicase Prp43p during ribosome biogenesis. Nucleic Acids Res 42: 7330-7345. doi:10.1093/nar/gku357

Chen JS, Ma E, Harrington LB, Da Costa M, Tian X, Palefsky JM, Doudna JA. 2018a. CRISPR-Cas12a target binding unleashes indiscriminate single-stranded DNase activity. Science 546: eaar6245. doi:10.1126/science.aar6245

Chen MC, Tippana R, Demeshkina NA, Murat P, Balasubramanian S, Myong S, Ferré-D'Amaré AR. 2018b. Structural basis of G-quadruplex unfolding by the DEAH/RHA helicase DHX36. Nature 558: 465-469. doi:10.1038/s41586-018-0209-9

Chen W-F, Réty S, Guo H-L, Dai Y-X, Wu W-Q, Liu N-N, Auguin D, Liu Q-W, Hou X-M, Dou S-X, et al. 2018c. Molecular mechanistic insights into Drosophila DHX36-mediated G-quadruplex unfolding: a structure-based model. Structure 26: 403-415.e4. doi:10 .1016/j.str.2018.01.008

Cheng J, Kellner N, Berninghausen O, Hurt E, Beckmann R. 2017. 3.2A-resolution structure of the $90 \mathrm{~S}$ preribosome before A1 pre-rRNA cleavage. Nat Struct Mol Biol 24: 954-964. doi:10.1038/nsmb .3476

Choudhury P, Hackert P, Memet I, Sloan KE, Bohnsack MT. 2018. The human RNA helicase DHX37 is required for release of the U3 snoRNP from pre-ribosomal particles. RNA Biol 497: 1-15. doi:10.1080/15476286.2018.1556149

Colley A, Beggs JD, Tollervey D, Lafontaine DL. 2000. Dhr1p, a putative DEAH-box RNA helicase, is associated with the box C+D snoRNP U3. Mol Cell Biol 20: 7238-7246. doi:10.1128/MCB.20 .19.7238-7246.2000

Emsley P, Cowtan K. 2004. Coot: model-building tools for molecular graphics. Acta Crystallogr D Biol Crystallogr 60: 2126-2132. doi:10.1107/S0907444904019158

Fairman-Williams ME, Guenther U-P, Jankowsky E. 2010. SF1 and SF2 helicases: family matters. Curr Opin Struct Biol 20: 313-324. doi:10.1016/j.sbi.2010.03.011

Gilbert LA, Horlbeck MA, Adamson B, Villalta JE, Chen Y, Whitehead EH, Guimaraes C, Panning B, Ploegh HL, Bassik MC, et al. 2014. Genome-scale CRISPR-mediated control of gene repression and activation. Cell 159: 647-661. doi:10.1016/j.cell .2014.09.029

Gradia SD, Ishida JP, Tsai M-S, Jeans C, Tainer JA, Fuss JO. 2017. MacroBac: new technologies for robust and efficient large-scale production of recombinant multiprotein complexes. Methods Enzymol 592: 1-26. doi:10.1016/bs.mie.2017.03.008

Granneman S, Bernstein KA, Bleichert F, Baserga SJ. 2006. Comprehensive mutational analysis of yeast DEXD/H box RNA helicases required for small ribosomal subunit synthesis. Mol Cell Biol 26: 1183-1194. doi:10.1128/MCB.26.4.1183-1194.2006
Hamann F, Enders M, Ficner R. 2019. Structural basis for RNA translocation by DEAH-box ATPases. Nucleic Acids Res 3: a003707. doi:10.1093/nar/gkz150

Hayward S, Berendsen HJ. 1998. Systematic analysis of domain motions in proteins from conformational change: new results on citrate synthase and T4 lysozyme. Proteins 30: 144-154. doi:10 .1002/(SICI)1097-0134(19980201)30:2<144::AID-PROT4>3.0.CO ;2-N

Hayward S, Kitao A, Berendsen HJ. 1997. Model-free methods of analyzing domain motions in proteins from simulation: a comparison of normal mode analysis and molecular dynamics simulation of lysozyme. Proteins 27: 425-437. doi:10.1002/(SICI)1097-0134 (199703)27:3<425::AID-PROT10>3.0.CO;2-N

$\mathrm{He}$ Y, Andersen GR, Nielsen KH. 2010. Structural basis for the function of DEAH helicases. EMBO Rep 11: 180-186. doi:10.1038/embor .2010 .11

He Y, Staley JP, Andersen GR, Nielsen KH. 2017. Structure of the DEAH/RHA ATPase Prp43p bound to RNA implicates a pair of hairpins and motif $\mathrm{Va}$ in translocation along RNA. RNA 23: 1110-1124. doi:10.1261/rna.060954.117

Heininger AU, Hackert $P$, Andreou AZ, Boon K-L, Memet I, Prior M, Clancy A, Schmidt B, Urlaub H, Schleiff E, et al. 2016. Protein cofactor competition regulates the action of a multifunctional RNA helicase in different pathways. RNA Biol 13: 320-330. doi:10 .1080/15476286.2016.1142038

Henras AK, Plisson-Chastang C, O'Donohue M-F, Chakraborty A, Gleizes P-E. 2015. An overview of pre-ribosomal RNA processing in eukaryotes. WIREs RNA 6: 225-242. doi:10.1002/wrna .1269

Hilbert M, Karow AR, Klostermeier D. 2009. The mechanism of ATPdependent RNA unwinding by DEAD box proteins. Biol Chem 390: 1237-1250. doi:10.1515/BC.2009.135

Holm L, Sander C. 1995. Dali: a network tool for protein structure comparison. Trends Biochem Sci 20: 478-480. doi:10.1016/S09680004(00)89105-7

Jankowsky E. 2011. RNA helicases at work: binding and rearranging. Trends Biochem Sci 36: 19-29. doi:10.1016/j.tibs.2010.07 .008

Jankowsky E, Fairman ME. 2007. RNA helicases-one fold for many functions. Curr Opin Struct Biol 17: 316-324. doi:10.1016/j.sbi .2007 .05 .007

Jarmoskaite I, Russell R. 2014. RNA helicase proteins as chaperones and remodelers. Annu Rev Biochem 83: 697-725. doi:10.1146/ annurev-biochem-060713-035546

Kabsch W. 2010. XDS. Acta Crystallogr D Biol Crystallogr 66: 125132. doi:10.1107/S0907444909047337

Kressler D, Hurt E, Baßler J. 2017. A puzzle of life: crafting ribosomal subunits. Trends Biochem Sci 42: 640-654. doi:10.1016/j.tibs .2017.05.005

Lackner DH, Carré A, Guzzardo PM, Banning C, Mangena R, Henley T, Oberndorfer S, Gapp BV, Nijman SMB, Brummelkamp TR, et al. 2015. A generic strategy for CRISPR-Cas9-mediated gene tagging. Nat Commun 6: 10237. doi:10.1038/ncomms 10237

Lebaron S, Papin C, Capeyrou R, Chen Y-L, Froment C, Monsarrat B, Caizergues-Ferrer M, Grigoriev M, Henry Y. 2009. The ATPase and helicase activities of Prp43p are stimulated by the G-patch protein Pfa1p during yeast ribosome biogenesis. EMBO J 28: 3808-3819. doi:10.1038/emboj.2009.335

Levin MK, Gurjar MM, Patel SS. 2003. ATP binding modulates the nucleic acid affinity of hepatitis C virus helicase. J Biol Chem 278: 23311-23316. doi:10.1074/jbc.M301283200

Linder P, Jankowsky E. 2011. From unwinding to clamping-the DEAD box RNA helicase family. Nat Struct Mol Biol 12: 505516. doi:10.1038/nrm3154 
Martin R, Straub AU, Doebele C, Bohnsack MT. 2014. DExD/H-box RNA helicases in ribosome biogenesis. RNA Biol 10: 4-18. doi:10.4161/rna.21879

McCoy AJ, Grosse-Kunstleve RW, Adams PD, Winn MD, Storoni LC, Read RJ. 2007. Phaser crystallographic software. J Appl Crystallogr 40: 658-674. doi:10.1107/S0021889807021206

Ozgur S, Buchwald G, Falk S, Chakrabarti S, Prabu JR, Conti E. 2015. The conformational plasticity of eukaryotic RNA-dependent ATPases. FEBS J 282: 850-863. doi:10.1111/febs.13198

Peña C, Hurt E, Panse VG. 2017. Eukaryotic ribosome assembly, transport and quality control. Nat Struct Mol Biol 24: 689-699. doi:10 .1038/nsmb.3454

Phipps KR, Charette JM, Baserga SJ. 2010. The small subunit processome in ribosome biogenesis-progress and prospects. WIREs RNA 2: 1-21. doi:10.1002/wrna.57

Prabu JR, Müller M, Thomae AW, Schüssler S, Bonneau F, Becker PB, Conti E. 2015. Structure of the RNA helicase MLE reveals the molecular mechanisms for uridine specificity and RNA-ATP coupling. Mol Cell 60: 487-499. doi:10.1016/j.molcel.2015.10.011

Pyle AM. 2008. Translocation and unwinding mechanisms of RNA and DNA helicases. Annu Rev Biophys 37: 317-336. doi:10.1146/ annurev.biophys.37.032807.125908

Robert-Paganin J, Réty S, Leulliot N. 2015. Regulation of DEAH/RHA helicases by G-patch proteins. Biomed Res Int 2015: 1-9. doi:10 $.1155 / 2015 / 931857$

Robert-Paganin J, Halladjian M, Blaud M, Lebaron S, Delbos L, Chardon F, Capeyrou R, Humbert O, Henry Y, Henras AK, et al. 2016. Functional link between DEAH/RHA helicase Prp43 activation and ATP base binding. Nucleic Acids Res 45: 1539-1552.

Sardana R, Zhu J, Gill M, Johnson AW. 2014. Physical and functional interaction between the methyltransferase Bud23 and the essential DEAH-box RNA helicase Ecm16. Mol Cell Biol 34: 22082220. doi:10.1128/MCB.01656-13

Sardana R, Liu X, Granneman S, Zhu J, Gill M, Papoulas O, Marcotte EM, Tollervey D, Correll CC, Johnson AW. 2015. The DEAH-box helicase Dhr1 dissociates U3 from the pre-rRNA to promote formation of the central pseudoknot. PLoS Biol 13: e1002083. doi:10.1371/journal.pbio.1002083
Schmitt A, Hamann F, Neumann P, Ficner R. 2018. Crystal structure of the spliceosomal DEAH-box ATPase Prp2. Acta Crystallogr D Struct Biol 74: 643-654. doi:10.1107/S2059798318006356

Sengoku T, Nureki O, Nakamura A, Kobayashi S, Yokoyama S. 2006. Structural basis for RNA unwinding by the DEAD-box protein Drosophila Vasa. Cell 125: 287-300. doi:10.1016/j.cell.2006.01 .054

Sloan KE, Bohnsack MT. 2018. Unravelling the mechanisms of RNA helicase regulation. Trends Biochem Sci 43: 237-250. doi:10 .1016/j.tibs.2018.02.001

Tanaka N, Schwer B. 2005. Characterization of the NTPase, RNAbinding, and RNA helicase activities of the DEAH-box splicing factor Prp22. Biochemistry 44: 9795-9803. doi:10.1021/bi050407m

Tauchert MJ, Fourmann J-B, Lührmann R, Ficner R. 2017. Structural insights into the mechanism of the DEAH-box RNA helicase Prp43. elife 6: e21510. doi:10.7554/eLife.21510

Walbott H, Mouffok S, Capeyrou R, Lebaron S, Humbert O, van Tilbeurgh H, Henry Y, Leulliot N. 2010. Prp43p contains a processive helicase structural architecture with a specific regulatory domain. EMBO J 29: 2194-2204. doi:10.1038/emboj.2010.102

Woolford JL, Baserga SJ. 2013. Ribosome biogenesis in the yeast Saccharomyces cerevisiae. Genetics 195: 643-681. doi:10.1534/ genetics.113.153197

Yang Q, Del Campo M, Lambowitz AM, Jankowsky E. 2007. DEADbox proteins unwind duplexes by local strand separation. Mol Cell 28: 253-263. doi:10.1016/j.molcel.2007.08.016

Zemp I, Wild T, O'Donohue M-F, Wandrey F, Widmann B, Gleizes P-E, Kutay U. 2009. Distinct cytoplasmic maturation steps of $40 S$ ribosomal subunit precursors require hRio2. J Cell Biol 185: 11671180. doi:10.1083/jcb.200904048

Zhu J, Liu X, Anjos M, Correll CC, Johnson AW. 2016. Utp14 recruits and activates the RNA helicase Dhr1 to undock U3 snoRNA from the preribosome. Mol Cell Biol 36: 965-978. doi:10.1128/MCB .00773-15

Zwart PH, Afonine PV, Grosse-Kunstleve RW, Hung L-W, loerger TR, McCoy AJ, McKee E, Moriarty NW, Read RJ, Sacchettini JC, et al. 2008. Automated structure solution with the PHENIX suite. Methods Mol Biol 426: 419-435. doi:10.1007/978-1-60327-058-8_28 
RNA 25: 685-701 (2019)

\section{Corrigendum: Molecular mechanism of the RNA helicase DHX37 and its activation by UTP14A in ribosome biogenesis}

FRANZISKA M. BONEBERG, TOBIAS BRANDMANN, LENA KOBEL, JASMIN VAN DEN HEUVEL, KATJA BARGSTEN, LUKAS BAMMERT, ULRIKE KUTAY, and MARTIN JINEK

An incorrect Supplemental Material file was inadvertently uploaded for the above-mentioned article. The correct file is now available online in the Revised Supplemental Material link.

The authors regret any inconvenience this has caused.

doi:10.1261/rna.072900.119 

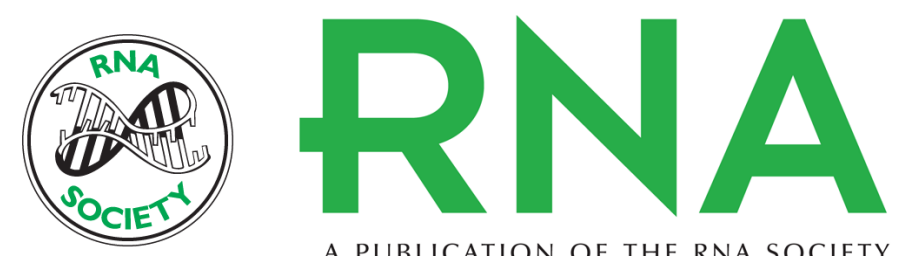

A PUBLICATION OF THE RNA SOCIETY

\section{Molecular mechanism of the RNA helicase DHX37 and its activation by UTP14A in ribosome biogenesis}

Franziska M. Boneberg, Tobias Brandmann, Lena Kobel, et al.

RNA 2019 25: 685-701 originally published online March 25, 2019

Access the most recent version at doi:10.1261/rna.069609.118

\section{Supplemental http://rnajournal.cshlp.org/content/suppl/2019/03/25/rna.069609.118.DC1 \\ Material http://rnajournal.cshlp.org/content/suppl/2019/09/16/rna.069609.118.DC2}

Related Content Corrigendum: Molecular mechanism of the RNA helicase DHX37 and its activation by UTP14A in ribosome biogenesis

Franziska M. Boneberg, Tobias Brandmann, Lena Kobel, et al.

RNA November , 2019 25: 1576

References This article cites 59 articles, 12 of which can be accessed free at:

http://rnajournal.cshlp.org/content/25/6/685.full.html\#ref-list-1

Articles cited in:

http://rnajournal.cshlp.org/content/25/6/685.full.html\#related-urls

Open Access Freely available online through the RNA Open Access option.

Creative This article, published in RNA, is available under a Creative Commons License

Commons (Attribution-NonCommercial 4.0 International), as described at

License http://creativecommons.org/licenses/by-nc/4.0/.

Email Alerting Receive free email alerts when new articles cite this article - sign up in the box at the Service top right corner of the article or click here.

To subscribe to $R N A$ go to:

http://rnajournal.cshlp.org/subscriptions 